\title{
The Role of Ethnic Malls in Placemaking: A Case Study of First Markham Place
}

\author{
by \\ Philip Liu \\ B.E.S., Planning, University of Waterloo, 2013
}

\author{
A Major Research Paper \\ Presented to Ryerson University \\ in partial fulfillment of the \\ requirements for the degree of \\ Master of Planning \\ In Urban Development
}

Toronto, Ontario, Canada, 2015

(c) Philip Liu 2015 


\section{Author's Declaration}

I hereby declare that I am the sole author of this MRP. This is a true copy of the MRP, including any required final revisions.

I authorize Ryerson University to lend this MRP to other institutions or individuals for the purpose of scholarly research.

I further authorize Ryerson University to reproduce this MRP by photocopying or by other means, in total or in part, at the request of other institutions or individuals for the purpose of scholarly research.

I understand that my MRP may be made electronically available to the public. 


\title{
THE ROLE OF ETHNIC MALLS IN PLACEMAKING: A CASE STUDY OF FIRST MARKHAM PLACE
}

\author{
(C) Philip Liu, 2015 \\ Master of Planning \\ in \\ Urban Development \\ Ryerson University
}

\begin{abstract}
This study examines the role and effectiveness of suburban, ethnic shopping centres in providing an alternative to public space. It is a response to the suburb's lack of good public spaces, and the resulting lack of community and sense of place, and is informed by the development of 'ethnoburbs' across North America. This study explores themes revealed by both literature and a series of field observations and intercept interviews. A case study analyzing First Markham Place and how its mall patrons use the space revealed implications regarding the effectiveness of these malls as public spaces. The author found that the mall's role as a community hub provides opportunities to satisfy both practical and innate desires for cultural goods, services, and co-ethnic interactions, encourages a 'public life' not seen in conventional suburban malls, and creates a unique sense of place for members of the target ethnic community as well as non-members.
\end{abstract}

Key words: Placemaking, public space, third places, ethnoburbs, multiculturalism 


\section{Acknowledgements}

I would like to take this opportunity to thank and acknowledge all the people that have inspired and helped me write this MRP. I surely would not have been able to do it without the following people.

First I would like to thank my academic supervisor Dr. Zhixi Zhuang for her guidance, ideas, and inspiration. Learning about her interesting research on multicultural cities and ethnic retail landscapes helped spark my interest in researching the topic of ethnic indoor shopping centres. Furthermore I found her thoughtful insight, suggestions, and comments very helpful in writing this paper. I would also like to thank my second reader Dr. Pamela Robinson for her thoughtful suggestions and comments as well. I also thank her for brainstorming with me before I finalized a research topic and inspiring me to look at the placemaking qualities of 'third places'.

Next I would like to thank my friends and classmates, as well as my recent and former coworkers for all the emotional, spiritual, and intellectual support they have provided me. Whether it be sharing their academic experiences, helping me brainstorm ideas, or simply providing words of encouragement; everything they have done for me was very important and I thank them for it.

Finally I would like to thank my family for their love, care, and support over the years. This topic is one that is close to my heart and inspired by my own life experiences. Without them none of this would be possible. 


\section{TABLE OF CONTENTS}

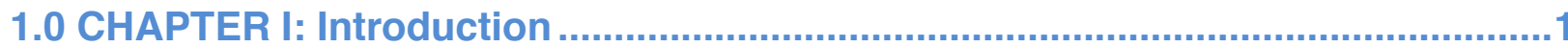

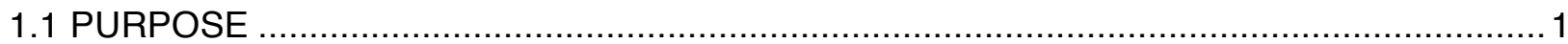

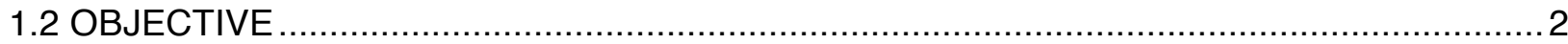

2.0 CHAPTER II: Background \& Literature Review ..............................................4

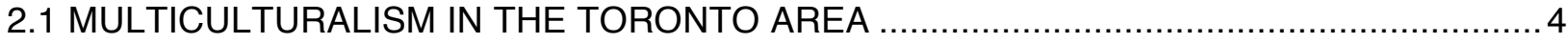

2.1.1 Immigration in Canada and Toronto: A Continuing Trend ........................................ 4

2.1.2 Land Use Planning for Multicultural Communities .................................................... 5

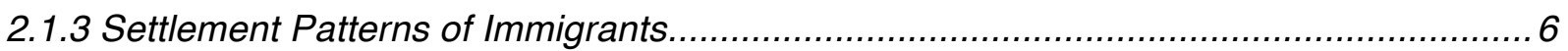

2.1.4 Reasons for concentration: The increasing relevance of 'pull' factors.........................8

2.2 SURBURBAN SHOPPING MALLS AS INFORMAL PUBLIC SPACES ........................... 12

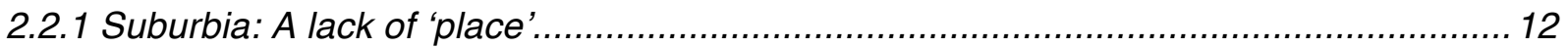

2.2.2 Shopping malls: The new Main Street? ...................................................... 13

2.2.3 Criticisms of shopping malls as public spaces.............................................. 17

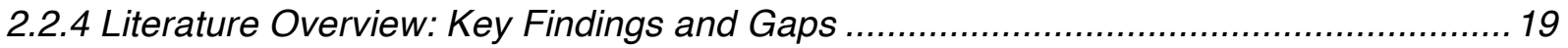

3.0 CHAPTER III: Methodology ..........................................................................22

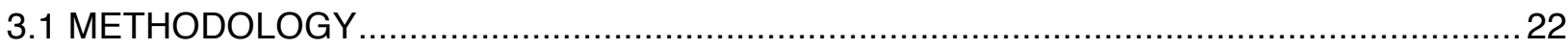

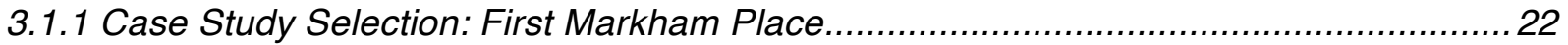

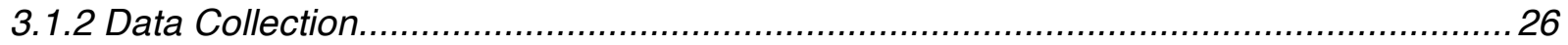

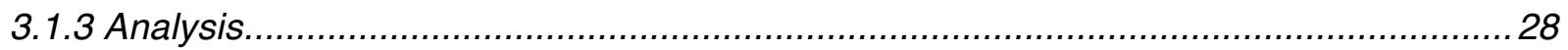

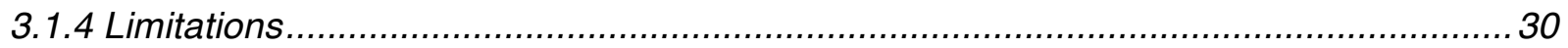

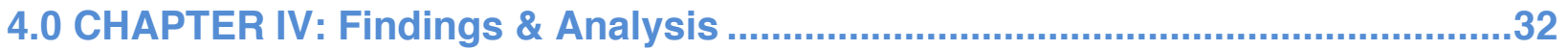

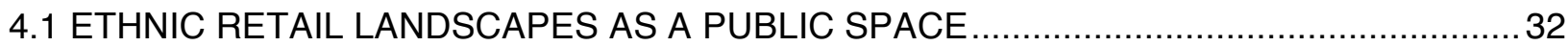


4.1.1 Are ethnic malls a good 'third place'? : 'Public life' and sociability............................ 32

4.1.1.1 Accessibility, accommodation, and 'the regulars'....................................... 33

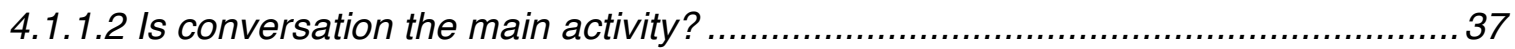

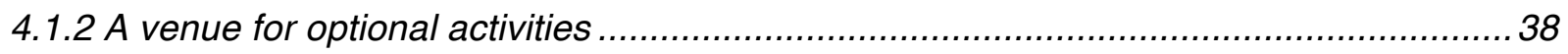

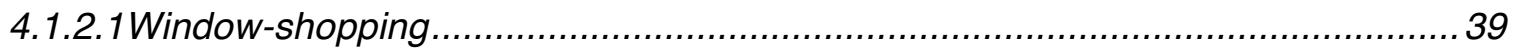

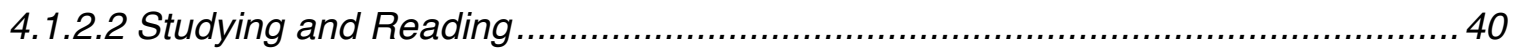

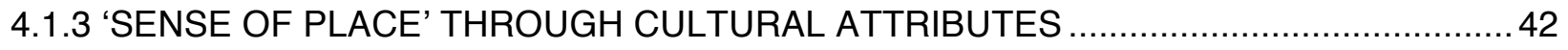

4.1.4 Cultural preferences for ethnic goods \& services and its significance...................... 43

4.1.5 Stores catering to cultural practices and traditions ......................................... 45

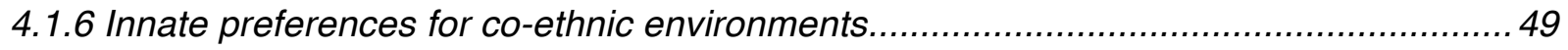

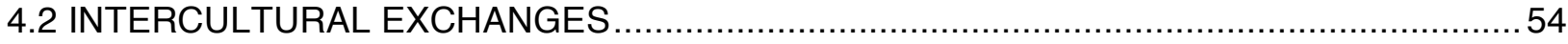

4.2.1 Experiences of non-ethnic patrons within ethnic malls ..................................... 55

4.2.2 Physical manifestations of intercultural exchange ........................................... 59

5.0 CHAPTER V: Conclusions \& Next Steps....................................................62

5.1 OVERALL INSIGHTS AND ADDITIONAL ANALYSIS ............................................ 62

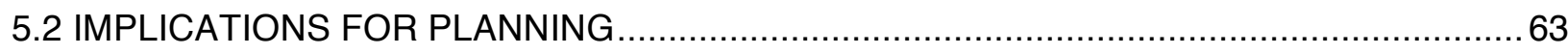

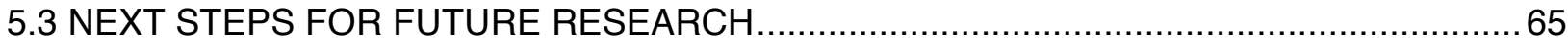

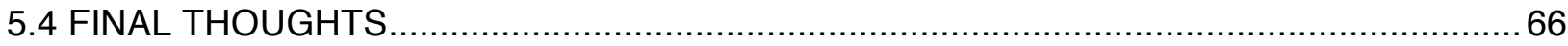

APPENDICES ....................................................................................................68

REFERENCES ....................................................................................................70 


\section{LIST OF FIGURES}

Figure 1. Diagram of First Markham Place \& Adjacent power centre $\ldots \ldots \ldots \ldots \ldots \ldots \ldots . \ldots 23$

Figure 2. Front Entrance view of First Markham Place Shopping Centre.............23

Figure 3. View of restaurants in the 'strip plaza' section of First Markham Place.......24

Figure 4. View of some of the 'mainstream' stores including NCIX, Bowring, and former Jacob Outlets

Figure 5. View of the adjacent 'Woodside' Smart Centre, with stores including Staples, Chapters, The Shoe Company, Roots Outlet, and more .25

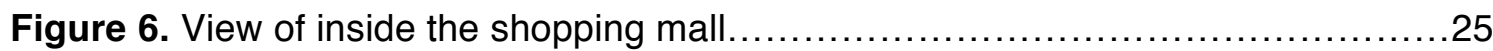

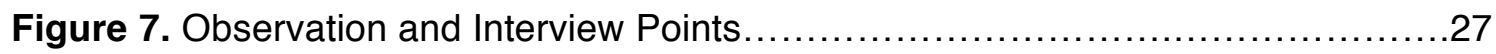

Figure 8. View of people doing a traditional 'fan dance' exercise in the morning........35

Figure 9. View of independent groups not affiliated with the social club doing tai chi in the morning..... 36

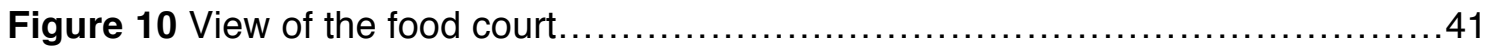

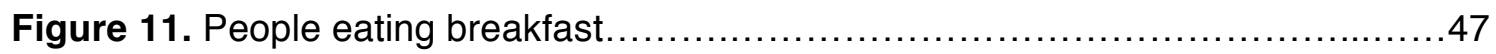

Figure 12. A make-shift booth selling flowers on Chinese New Years Eve.............48

Figure 13. One of a few stores opened past regular hours on Chinese

New Years Eve selling lucky Chinese New Year items.

Figure 14. The food court during the Lion Dance performance, with a noticeably large presence of children and strollers.

Figure 15. 'Lion Dancers' perform the 'plucking the green' ritual, a tradition considered lucky for the storeowner. Lettuce was hung from any stores that wanted to participate.

Figure 16 Mayor Frank Scarpitti of the City of Markham addressing the audience during the Chinese New Years Eve show....

Figure 17. A view of Home Outfitters, Cineplex Odeon, and Golf Town at First Markham Place.

Figure 18. Chinese New Year decorations sponsored by Canada Dry, and a Bell Canada advertisement for Chinese New Year. 


\section{LIST OF APPENDICES}

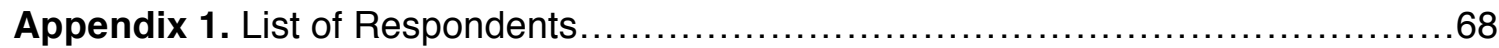

Appendix 2. Optional \& Necessary Activities (Gehl et al., 2006) ....................69 


\subsection{CHAPTER I: Introduction}

\subsection{PURPOSE}

Canada has long been considered a nation of immigrants. As with in the United States, ethnic enclaves have become an important phenomenon within the study of demography within North America. A look at the current demographics of today's major Canadian cities shows that 'ethnoburbs' are a defining aspect of life for many of Canada's ethnic minorities. Ethnoburbs are a specific form of the ethnic enclave found in suburban communities, a contrast from traditional ethnic enclaves typically found in the city centre.

Meanwhile, literature on North American suburbia has suggested that suburbanites are often devoid of the community, sense of place, and accessibility to public space found in traditional city centres. The development of large indoor malls has been seen as both a manifestation of sterile urban design, loneliness, and exclusivity, but also an alternative or replacement to not only traditional retail environments but also traditional public spaces.

While the topics of ethnoburbs and the lack of 'community' found in today's suburbs do not seem to be closely linked at first, they are in fact defining aspects of contemporary Canadian society. Some have suggested that ethnic minority groups in North America are especially in need of public spaces due to "status quo effectively excluding certain ways different ethnocultural groups uses public spaces" (Frisken and Wallace, 2002; Merraro, 2011; as quoted in Galanaskis, 2013). Meanwhile Sandercock 
writes "immigrants have a particularly strong need for community (Sandercock, 2003).

One place where both topics converge is the ethnic indoor shopping mall. In perhaps a paradoxical way, these retail landscapes represent both suburbia's lack of place and community, but also an important hub within ethnic communities.

Therefore the purpose of this paper is to gain insight into the effectiveness of indoor malls in creating a sense of place and a quality alternative to public space for suburbanites given the added dimension of ethnic-specific services, stores, and marketing. This is in recognition of the idea that "a good place has less to do with how a space looks than how people use it: the activities that go on there, how comfortable it is...the public image it projects" (Kent, 2000, para.5). This is significant in that it will add to the academic understanding of life in the suburbs, as well as life for ethnic minorities. From a land use planning perspective, this study will help inform planners and city builders on what is working and what needs to be changed in the urban fabric of today's suburban communities. It will also provide insight on the habits of Canada's ethnic communities, and the implications that may have on retail and multicultural planning.

\subsection{OBJECTIVE}

The key objective of this paper is to explore how users of First Markham Place, an ethnic mall chosen for the case study which this paper will focus on, use the space at the shopping centre and retail plaza. It will look to answer the following two research questions:

- What roles do these malls play within the community as an alternative to 


\section{public space?}

- How effective are suburban ethnic malls in providing a good alternative to public space? Can suburban ethnic malls evoke a unique 'sense of place' to members of the community?

With these research questions in mind, an analysis will be conducted on the primary data collected in hopes of providing a better understanding of these retail landscapes as a place for community and a sense of place and/or belonging.

Before explaining the methodological approach this paper will use to address the research questions, some context will be provided through some background information and a brief literature review. 


\subsection{CHAPTER II: Background \& Literature Review}

The following chapter will provide a review of some of the key academic works relating to multiculturalism, ethoburbs, place-making, and shopping mall culture in North America. The purpose of this literature review is to provide some context around what influenced this study. Some key demographic and geographic information will also be provided, as well as a brief discussion on multicultural planning to help frame a concluding section on the planning implications of an increasingly multicultural society.

\subsection{MULTICULTURALISM IN THE TORONTO AREA}

\subsubsection{Immigration in Canada and Toronto: A Continuing Trend}

Canada is a 'nation of immigrants', and nowhere is this more apparent than in the nation's largest metropolitan area, Toronto. In $2011,20.6 \%$ of Canada's population was immigrants, the highest proportion out of all the G8 countries (Statistics Canada, 2011). $37.4 \%$ of the immigrant population in Canada lived in the Toronto CMA, by far the largest share of immigrants among Canada's urban centres. The metropolitan area also has the largest proportion of immigrants out of Canada's three largest urban centres, with $46 \%$ of the Toronto CMA's total population being foreign-born, more than $40 \%$ in Vancouver and 22.6\% in Montreal (Statistics Canada, 2011).

Indeed, this trend is expected to continue into the future. With $62.5 \%$ of immigrants between 2006-2011 choosing to live in the nation's three largest urban centres, newcomers are continuing to disproportionately settle in the nation's largest cities. During this period, 381,700 newcomers decided to settle in the Toronto CMA, about 
one-third $(35.2 \%)$ of the total number of immigrants to settle in Canada, above Montreal and Vancouver which saw 189,700 (17.5\%) and 155,100 (14.3\%) immigrant newcomers respectively (Statistics Canada, 2011). Looking into the future, it is expected that around three in ten Canadians will be a member of a visible minority group by 2031 , and that South Asians and Chinese will continue being the largest visible minority group (Malenfant et al. 2009). Much of this will be the result of continued immigration from non-European countries. By 2031 , more than $71 \%$ of visible minorities will live in Toronto, Montreal, or Vancouver. Furthermore, 55\% of all Canadians living in CMAs and up to $78 \%$ of persons living in the Toronto CMA will either be immigrants or secondgeneration immigrats (Malenfant et al. 2009). Therefore the study of immigrant culture and placemaking for immigrants is a significant topic to consider.

\subsubsection{Land Use Planning for Multicultural Communities}

Despite the increasingly large multicultural population in Canada, land use planning practices and policies do not seem to reflect this. In fact, academic literature on multicultural societies around the world including Canada has shone a light on the "failure of the planning system to respond to the increasing cultural diversity of the city" (Sandercock, 2003, p.129). Challenges identified from a wide body of literature include the fact that values and norms of dominant culture are "usually embedded in legislative frameworks, [...] attitudes, behaviour, and practices of actual flesh-and-blood planers [due to] cultural misunderstanding, [...] and racism within communities" (Sandercock, 2003, p.131).

Sandercock wrote, "multiculturalism in Canada has served as a guideline for 
government policy since $1971 \ldots$ [and] encouraged individuals voluntarily to affiliate with the culture and tradition of their choice. [Efforts have ranged from] significant spending, through multicultural grants, to supporting the maintenance of various cultures and languages" (Sandercock, 2003, p.142). However, she also wrote that despite the quality of multicultural policies at the national level, "provincial and local levels of governments have been slower to respond to cultural diversity in terms of examining and changing their policies" (Sandercock, 2003, p.143). Furthermore, "research in [...] Toronto has shown that local policies in relation to the built environment have lagged behind the rapidly changing demographic realities" (Sandercock, 2003, p.143). Meanwhile studies on Richmond Hill and Markham have shown that policies have only been "somewhat responsive" to immigrants and ethnic minorities, and that both municipalities tend to be "reactive" more so than "proactive" (Good, 2005, p.6). Therefore it is important that land use planning policies are changed to better reflect increasingly multicultural communities in Canada. While this paper will not focus on these planning implications, a further analysis will be briefly discussed in the concluding chapter's section $\mathbf{5 . 2}$

\section{Implications for Planning.}

\subsubsection{Settlement Patterns of Immigrants}

Immigrants and ethnic minorities in North America, and even the world, have been observed to cluster together. While the reason for clustering varies over time and in different locations, it is a phenomenon that is well documented in academic literature (Wen, 2009; Qadeer et al., 2010; Qadeer \& Kumar, 2006). The spatial distribution of the immigrant and ethnic minority population in the Toronto CMA is no different. Indeed, 
Toronto has a "long history of ethnic neighbourhoods," from the Irish Catholics in Cabbagetown during the Victorian era to Eastern European Jews in St. John's Ward during the WWI (Qadeer \& Kumar, 2006). However, many of Toronto's immigrant communities have migrated out of the city centre and into the suburbs, a phenomenon that has been occurring not only in Canada but throughout the United States as well (Wen, 2009). Whether it is the Chinese community in Monterey Park outside Los Angeles, or the large Hispanic community in West Dallas, these suburban ethnic enclaves, or 'ethnoburbs' as coined by Wei Li in 1997, represent some of the largest concentrations of immigrants and ethnic minorities on the continent. Ethnoburbs are defined as "suburban ethnic clusters of residential areas and business districts in large...metropolitan areas" (Li, 1998, p.479).

In Toronto, the only major ethnic enclave that still exists within the city centre is the Jewish community around Bathurst Street (Qadeer \& Kumar, 2006), and perhaps the Somali's in Rexdale. More traditional communities like Chinatown, Little Italy, and the Portuguese village "are relatively small and secondary" (Qadeer \& Kumar, 2006; Qadeer et al., 2010). Along with the City of Toronto, Mississauga, Brampton, and Markham currently have the largest population of ethnic minorities and together are home to over $85 \%$ of the CMA's visible minority population (Statistics Canada, 2011). Without the City of Toronto, which itself includes significant visible minority populations in its suburban communities, Mississauga, Brampton, and Markham alone makes up $36 \%$ of the CMA's visible minority population (Statistics Canada, 2011). In fact, the two

\footnotetext{
${ }^{1}$ A primary concentration as defined by Qadeer (2006) is one where more than $50 \%$ of the census tract's population is of one ethnic background. Secondary concentrations are when an ethnic group is the largest ethnic group without being a majority, generally $25 \%-49 \%$ of the census tract's population.
} 
largest and most distinct ethnic 'sectors' are the concentration of the Chinese population in the northeast portion of the metropolitan area, and the Italian ethnic concentration in Vaughan's Woodbridge community (Qadeer \& Kumar, 2006). Between 2001 and 2006 alone, the percentage of the Chinese and South Asian population in the Toronto CMA living in their respective ethnic enclaves grew from $28 \%$ and $30 \%$ respectively to $48.2 \%$ and $49.6 \%$ (Qadeer, 2010). Indeed, 'ethnoburbs' best represents the face of the ethnic population in today's Greater Toronto Area.

\subsubsection{Reasons for concentration: The increasing relevance of 'pull' factors}

Ethnic enclaves, including ethnoburbs, are formed due to a number of reasons, including both 'push' and 'pull' factors (Qadeer et al, 2010). Earlier on, 'push' factors appear to be more prominent as society made it relatively difficult for immigrants to settle without forming these enclaves, due to reasons including housing opportunities and discrimination (Qadeer et al, 2010; Wen, 2009). When immigrants first arrive, they often "have to live in poor neighbourhoods where they cluster along cluster lines" (Qadeer et al, 2010, p.320). Here, they have access to "affordable housing, social networks, helpful information on labour market or financial capital [without the language barrier], and a familiar culture" (Wen, 2009, p.427).

Over time however, the groups as a whole progress both socially and economically. They then often gradually move to more conventional, sometimes 'whiter', suburban neighbourhoods (Qadeer, 2010 et al.; Wen, 2009). This phenomenon is what some consider the spatial assimilation model. Furthermore, in recent years many new 
immigrants, particularly those from Asia, now arrive with more economic resources to from the start. Thus new immigrants are increasingly less constrained by the social and economic constraints that had previously forced them to cluster. This has allowed new immigrant and ethnic minority groups to become both socially and locationally assimilated (Qadeer, et al., 2010).

However as seen from today's ethnoburbs, it is apparent that this is not always the case. As Qadeer et al. writes, "the spatial assimilation model does not reflect the contemporary, reality of multiculturalism and pluralism" (2010, p.320). Many of today's ethnoburbs are examples of affluent immigrants that continue to live in ethnic enclaves. This has been explored in a study by Logan et al., which used certain neighbourhoods in the New York and Los Angeles areas as examples of how "living in ethnic neighbourhoods was unrelated to economic constraints [and thus] a violation of...the spatial assimilation model" (2002; as quoted in Wen, 2009, p.430). The aforementioned Chinese and Italian concentrations in the Toronto area are a Canadian example of affluent ethnic groups that continue to live in enclaves (Myles and Hou, 2004). For example a study by Environics Analytics divided Canada's population into socioeconomic 'segments' based on the income and lifestyles of Canadian communities. The most recent 2015 version of their research showed large concentrations of affluent immigrants in suburban Toronto and Vancouver with segments named 'Asian Sophisticates' and 'South Asian Achievers', reflecting the high incomes of households within these predominantly Asian communities (Sorensen, 2015). Therefore the rise of these 'ethnoburbs' is instead "largely attributed to...in-group attraction and purposive 
efforts in sustaining ethnic identity" (Wen, 2009, p.429). Ethnic minorities are no longer forced to concentrate together but instead choose to. It is based on motives "associated with taste and preference" (Wen, 2009, p.429), an example being the preference for ethnic supermarkets because they provide the opportunity to purchase food goods not available in other supermarkets. For this reason, academic literature now generally agrees that enclaves, including ethnoburbs, are increasingly "expressions of ethnic minorities' and immigrants' choices to form communities based on their values and interests" (Marcuse, 2005; Peach, 2005; Qadeer, 2005; Muller, 1993; as quoted in Qadeer at al., 2010) or 'pull factors'.

So now the questions are; what are the characteristics of these ethnoburbs? And what exactly are these pull factors? As with traditional, historic ethnic enclaves, ethnoburbs are homes to specific ethnic-catered businesses, services, places of worships, social clubs, and various other institutions. The concentrations of ethnic populations make these services and establishments economically viable, whether they are churches, restaurants, grocery stores, law firms, etc. (Qadeer et al., 2010). Indeed, many of the services and establishments that helped disadvantaged new immigrants survive when pushed by social and economic constraints are also what pulls and attracts wealthier ethnic minorities into these more affluent ethnic enclaves even when they are no longer pushed by the aforementioned constraints.

The pull factor is partly due to what scholars believe is a "natural tendency to live close with co-ethnics [or] natural ethnocentrism" (Wen, 2009, p.429). Ethnicity is an important part of many people's identity (Qadeer et al., 2010; Glazer and Moynihan, 
1963) and a shared identity can be an important pull factor as many people hope to sustain their ethnic identity (Qadeer et al., 2010; Wen, 2009). This is even more apparent when one looks at the fact that many of these enclaves "continue to thrive on the basis of ethnic identity and institutions in the second and third generations" (Qadeer et al., 2010, p.320). Many second and third generation immigrants are socially and economically no different than their non-immigrant counterparts, yet they still decide to live or take part in these enclaves. One can see that if they grew up in these ethnoburbs, this is even more likely to be true.

\subsubsection{Identity \& Sense of Place from Ethnic Establishments}

As mentioned earlier, it is not only the ethnic population that makes a community an ethnoburb, the ethnic establishments and institutions are also key characteristics to this settlement model. In particular, ethnic businesses are a key component to the ethnoburb model first established by Li (Li 1998; Wen, 2009). The ability to eat authentic ethnic foods, buy groceries at ethnic supermarkets, and shop at ethnic specific shopping centres is a key part in making ethnic minorities, especially new immigrants, "feel at home" (Li, 1998, p.483). Lo writes that when ethnic economic activities are clustered, they "create a special landscape. To members of the ethnic group, this is where socialization...is conducted in their own language and ethnic identities are reinforced" (2009, p.393). Wang writes that "the ethnic market assumes a cultural role, serving as an arena for renewing social ties and promoting a pattern of daily life in which regular shopping and social trips are carried out” (2004; as quoted in Lo, 2009, p.393). 
In a study on Chinese supermarkets in the Toronto area, Lo writes that Chinese supermarkets are "more than a grocery store to the Chinese - [they] convey nostalgia and [are] imbued with cultural values and practices, and serve as a social setting where Chinese identity is constructed reinforced, or negotiated" (Lo, 2009, p.410).

Thus, just like how an ethnoburb helps immigrants and ethnic minorities "keep close ties to their countries of origin" (Li, 1998, p.483) and provide a sense of place, the businesses and establishments within the ethnoburbs do the same.

\subsection{SURBURBAN SHOPPING MALLS AS INFORMAL PUBLIC SPACES}

\subsubsection{Suburbia: A lack of 'place"}

Suburban life, once described as the 'American dream', has since become widely criticized by scholars and urbanists across North America and even worldwide. Aside from it being environmentally unsustainable, much attention has focused on the lack of community and/or sense of place. Banerjee writes that there is a "general agreement that we are experiencing a steady withering of public realm" (Banerjee, 2001, p.9) as a result of an increasingly "privatized world of city building" (Rybczynski, 1999; as quoted in Banerjee, 2001, p.10). Ray Oldenburg describes suburbia as having a "problem of place" (1989, p.4). He describes suburbs as being a place of loneliness and isolation, with a lack of community, and claims that they are "hostile to space utilization beyond the house," in which individuals' lives are fragmented (Oldenburg, 1989, p.4). More specifically, Oldenburg blames this on the "absence of an informal public life" where there is "no third realm of satisfaction and social cohesion beyond the portals of home 
and work" (Oldenburg, 1989, p.9). This lack of an informal public life has resulted in a denial of a place to relieve stress (Oldenburg, 1989). He demonstrates this by citing how many European immigrants recognize this lack of community in the suburbs. While in Europe they could easily "stroll down to one of the local cafes," or bump into friends on the streets or at a variety of restaurants or shops, it is not possible in America (Oldenburg, 1989, p.5). Social arrangements need to be prearranged and often involves "a major investment of time and nervous strain in driving long distances" (Oldenburg, 1989, p.5). Using a term that Oldenburg has so famously coined, what suburbia is missing is the 'third place'. 'Third places', after one's home and workplace, and are an individual's 'first' and 'second' places, are "the core setting of informal public life" (Oldenburg, 1989, p.16). They may consist of a "variety of public places that host regular, voluntary, informal, and happily anticipated fathering of individuals beyond the realm of home and work" (Oldenburg, 1989). However, in suburban North American communities these "third places are neither prominent or prolific" (Oldenburg, 1989, p.17). Rather they are far and few between. Indeed places Oldenburg considers to be common 'third places' like pubs and coffee shops still exist, though not as accessible due suburban landscapes, but suburbanites are also relatively more individualistic and less likely to initiative social interactions with strangers.

\subsubsection{Shopping malls: The new Main Street?}

The indoor shopping mall has grown to become a key commercial hub within North American suburbia. It is a place where suburbanites spend a lot of their time in (Cohen, 2008), not only shopping but also seeking entertainment. Though Oldenburg 
largely disagrees with the following sentiment, he acknowledges the fact that many people consider shopping malls the 'new main street' (Oldenburg, 1989). Meanwhile other scholars have called it "the new downtown" (Rybcyznski, 1993, p.98) due to it being "perhaps the most ubiquitous and frequently visited placed today" (Kowinski, 1985; as quoted in Banerjee, 2001, p.13) and "de-facto community centres" (Brill, 2001, p.51). US News and World Report wrote "the shopping mall is replacing Main Street at the core of community belonging in America" (as quoted in Oldenburg, 1989, p.118). Some writers and scholars have even argued that shopping malls are greater than main streets, claiming that they "are attractive places where as the small town was ugly," and that they are "the most tranquil and pleasant environment...even found in suburbia" (as quoted in Oldenburg, 1989, p.118). Despite the many criticisms, which will be discussed later, one cannot dispute the large role it plays in the lives of North American suburbanites. Though it "lacks some of the true community aspects...it is a very relevant site of [North American] cultural identity" (Scharoun, 2012, p.68). In a more local study about the now defunct Morningside Mall in Scarbroough, Parlette \& Cowen writes, "social reproduction was a staple of mall life in addition to the consumption we know so much about" (Parlette \& Cowen, 2011).

The indoor shopping mall's role as a public space is intriguing in that even though it is supposed to replicate traditional public squares and Main Streets, "it is a fully privatized space [...] a vast gray area of pseudo-public private space" (Scharoun, 2012, p.88). They are "perfect examples" of "the synthesis of consumption sites and leisure activities" (Lowes, 2002, p. 24) that is today's main consumption sites. The lack of 
traditional public spaces has resulted in private retail spaces, like the indoor shopping mall, becoming the closest alternative to public spaces. In fact some developers and owners of indoor malls explicitly recognize this role shopping malls have come to play within their communities, as evident by a quick look at the profiles of some of these companies. For example Cadillac Fairview writes on their public website that they "believe in building mutually beneficial relationships by contributing to the health and wellness of the communities in which [they] operate...through services [they] provide...including the donation of in-kind space" ("Social Responsibility", 2014). Some developers even try to replicate this through aesthetic cues. For example one section of Vaughan Mills shopping centre is called the 'City Neighbourhood' and was designed according to the "diverse patterns and textures [that] bring a city block to life...suggest[ing] the characteristics of city movement, activity and excitement" (“DiscoverOntario", n.d.).

Indeed, the concept of 'privatized' public spaces is frequently mentioned within academic literature (Kowinski, 1985; Kowinski, 1985; Parlette \& Cowen, 2011; Banerjee, 2001; Gehl, 1987). Parlette \& Cowen writes, "enclosed malls...often become community space. While privately owned and managed, enclosed malls in inner suburbs are at times the only indoor spaces that offer some degree of public access" (Parlette and Cowen, 2011). It is true that for the many people that have grown up in the suburbs and are not familiar with the traditional main street, "the mall is their main street" (Scharoun, 2012, p.68). Like traditional main streets they are focal points within the community. They are meeting places. They are places where retail consumption and social 
interactions create a harmonious synergy and provide an exciting environment for its users.

For reasons that will be discussed later, Scharoun writes that "the mall is not an ideal community centre; however, it does serve as a primary site for community interaction for some demographic groups" (Scharoun, 2012, p.68). Different demographics have different needs that can be satisfied in many ways including ones need for community and public space. Depending on a specific demographic's own standards, what is accessible to them, and to what extent other spaces cater to their specific needs, the quality of a public or pseudo-public space to one demographic can vary from another.

For example it is argued by some that indoor shopping malls can provide important community space for elders and teenagers. Zukin mentions "elderly joggers" and 'teenagers" being examples of "those who 'resist' - yet also participate in - the public culture of mass consumption" by simply using the mall for non-consumption purposes, and that "the space is important to them, to framing their social identities" (Zukin, as quoted in Lowes, 2002, p. 23). Looking specifically at the importance of shopping malls to suburban teens, Scharoun writes, "the mall may not be an ideal space for everyone; however, for teenagers it has proven to be a very important social and formative space" (Scharoun, 2012, p.69). Devlin writes that the mall is not only a place to "shop, meet friends, and find temporary employment," but it is able to "alleviate social and intimate loneliness" (Devlin; as quoted in Scharoun, 2012, p.69) beyond simply the action of meeting with their peers. He writes that even if a teen does not have any 
friends or people to talk to, the mall, with its "bright and vibrant [atmosphere] with constant upbeat music playing...offers a positive and existing visual stimulation" (Devlin, as quoted in Scharoun, 2012, p.72). A teen does not necessarily need to talk to people at the mall, by simply browsing, buying what they want, or being in a space with other teens, it is already enough to "provide a feeling of social interaction" (Kim et al., as quoted in Scharoun, 2012, p.72). Meanwhile, Parlette and Cowen writes in their study about how Morningside Mall was an informal gathering place for South Asian seniors (Parlette \& Cowen, 2011). Thus for certain demographics, malls are not just places to consume goods and services but places in which its very environment provides a sense of place.

Indeed the act of teenagers and elders using the mall as space for nonconsumption leisure suggests that the shopping mall is an alternative to public space. In Gehl's New City Life and "People on Foot" article published in the Arkitekten architectural journal, he lists a variety of activities that can take place in public spaces and ranks them from 'optional' to 'necessary'. Activities that are optional are those that one does not have to do in a public space (eg. sitting to enjoy life), while necessary activities are those that have more utilitarian purposes (eg. walking to do an errand). (See Appendix 2). Seeing as the main purpose of shopping malls is to create a place to consume, non-consumption activities can be considered 'optional' activities and thus indicating the quality of shopping malls as alternatives to public spaces.

\subsubsection{Criticisms of shopping malls as public spaces}


While indoor shopping malls are considered by some to be the suburbs' closest equivalent to a 'main street' or 'downtown', many have also criticized its inability to truly recreate the vibrancy and social aspect of traditional public spaces and major thoroughfares. Critics have argued, "The community sentiment that the mall is attempting to relay...never really comes to fruition. The mall is a centrally controlled commercial space, less reliant on the symbiotic relationship between shopkeepers and townspeople than the real Main Street" (Scharoun, 2012, p.67). This is in stark contrast to traditional Main Streets that are public properties. However, people in shopping malls do not personally connect to the people around them. Since people drive to malls from a larger radius, the chances of customers seeing other regulars they know and recognize is smaller (Scharoun, 2012). In this regard, shopping malls are a stark contrast from what Oldenburg describes as an ideal 'third place'. According to Oldenburg, good community spaces are places that are 'accessible' and 'accommodating', in that anyone "may go alone at any time of the day with the assurance that acquaintances will be there" (Oldenburg, 1989, p.32). It is a place where there are 'regulars' and that speaking to these acquaintances is the main activity.

Oldenburg, Scharoun, and others also criticize the 'overly commercial' characteristic of shopping malls, arguing that they take away from the community aspect of the space. Oldenburg claims that the lack of social interaction within shopping malls mean "pleasures are reduced to consumerism" (Oldenburg, 1989, p.10). He claims that true "informal public life depends upon people finding and enjoying another outside of 
the cash nexus" (Oldenburg, 1989, p.11). Scharoun criticizes the controlled store hours, signage, and sales pitches as an illustration of the mall's monotonous and commercialdriven nature. Parlette and Cowen have written that indeed, "private retail space' is an accurate description of the enclosed mall, and 'creative destruction' captures well the capitalist cycle" (Parlette \& Cowen, 2011). They also mention that indoor malls have historically been considered exclusive based on factors like racism and heavy surveillance (Parlette \& Cowen, 2011). For all these factors, malls have generally been dismissed as a worthy alternative to traditional public spaces.

\subsubsection{Literature Overview: Key Findings and Gaps}

Despite the modest nature of this literature review, the academic literature reviewed here reveals a number of key findings that are well recognized by key and/or contemporary pieces of literature within their respective fields. The lack of public spaces and social interactions within suburbia has been a topic of discussion for many years, and is evident in iconic pieces of literature still well regarded today, like those by Oldenburg (1989) and Jacobs (1961). In response to that, a growing number of academic literature has discussed the role of privatized spaces acting as alternatives to

public space (Kowinski, 1985; Banerjee, 2001; Gehl, 1987). The idea of indoor shopping malls as an alternative to public spaces has been discussed and generally dismissed as being unsatisfactory (Oldenburg, 1999; Scharoun, 2012). Therefore one of the key themes this paper will look to explore is the role of shopping malls, especially ethnic malls, in providing an alternative to pubic space. 
Meanwhile looking at the literature on multiculturalism in North America and ethnoburbs, it is apparent that the desire to be with co-ethnics and have access to ethnic goods and services is a strong pull factor responsible for the growth of many of North America's largest ethnoburbs. Therefore another theme that this paper hopes to explore is the ethnic mall as a manifestation of cultural preferences and identity, and its role in placemaking. That said it is important to realize that ethnic malls are situated in communities in which other non-members of the predominant ethnic group exists. Indeed academic literature has focused on the place-making qualities of ethnoburbs and ethnic retailing for members of specific ethnic groups, but lacks a discussion on what type of place this creates for non-members of that ethnic group. Thus this paper will also explore what sense of place these ethnic malls give to non-members of the target ethnic group as well as the intercultural interactions they facilitate.

Despite a substantial body of work surrounding both topics, little is written on the implications that result from the marriage of both topics in the manifested form of the ethnic suburban shopping mall. Furthermore, it will respond to the gaps as well as calls for research in previous pieces of academic literature. Lo's study on Chinese supermarkets (2009) was a response to the gap that "we know little about coethnic consumers' responses to these [ethnic] businesses and even less about their impact on the general consumer market" (Lo, 2009, p. 393). This paper thus hopes to further her research by taking a larger focus on qualitative data (in contrast to her more quantitative approach) and the narratives of ethnic retail consumers. The paper will look to explore 
why and to what extent these landscapes evoke nostalgia and a feeling of identity. This paper will also look to transfer the scope from ethnic supermarkets to ethnic malls within the Toronto context. Furthermore this paper will look to respond to Twigger-Ross and Uzzel's claim that "despite the many studies using the concepts of place-identity and place attachment, few have provided a clear...account of the relationship between place and identity" (1996, p.205); and Manzo's writing that despite "an extensive and evergrowing body of literature [on placemaking]...these concepts are broadly defined [and] their application does not fully embrace all of the important dimensions of people's emotional relationships to places" (2003, p.47). 


\subsection{CHAPTER III: Methodology}

\subsection{METHODOLOGY}

\subsubsection{Case Study Selection: First Markham Place}

The primary research conducted for this paper will focus on First Markham Place Shopping Centre. The shopping centre is located on the south side of Highway 7 East, between Warden Avenue and Woodbine Avenue. It is located in Markham, Ontario - a city with an ethnic Chinese population of $39.6 \%$, the highest of any Canadian census subdivision after only Richmond, British Columbia. First Markham Place was chosen because it is less studied than the region's largest Chinese mall, Pacific Mall, and generally perceived of as less of a tourist attraction making it relatively more of a 'neighbourhood' mall (eg. Pacific Mall is often open on statutory holidays). Yet with over 180 retail stores, 22 sit-down restaurants, and 24 food court outlets, the complex is large enough in that it still attracts a significant amount of traffic and attention, being labeled by some popular media portals as "Markham's 'other' Chinese Mall" (Susilo, 2012, para.1). First Markham Place consists of both an indoor shopping mall as well as a strip plaza component. From the store selection, signs, marketing material, and the author's own knowledge of the Chinese culture from his own ethnic background of being from Chinese descent, the shopping mall's caters primarily to Chinese people. However, the ethnic-focus extends to other East Asian cultures as evident by a small number of Korean and Southeast Asian stores and restaurants.

What is unique about First Markham Place is that there are also conventional retail establishments within the complex, including a Cineplex Odeon multiplex movie theatre, 
a Home Outfitters, a NCIX computer store, and a Bowring (home accessories store). In addition, there is a Smart Centre power centre directly adjacent to First Markham Place with anchors including a Home Depot, Winners, Chapters, and Staples. Thus from a trip-making perspective, this shopping centre will provide a more multi-dimensional insight on the shopping habits of its users. For example, an individual's trip-making decision may be impacted if he/she had something to buy from Home Depot.

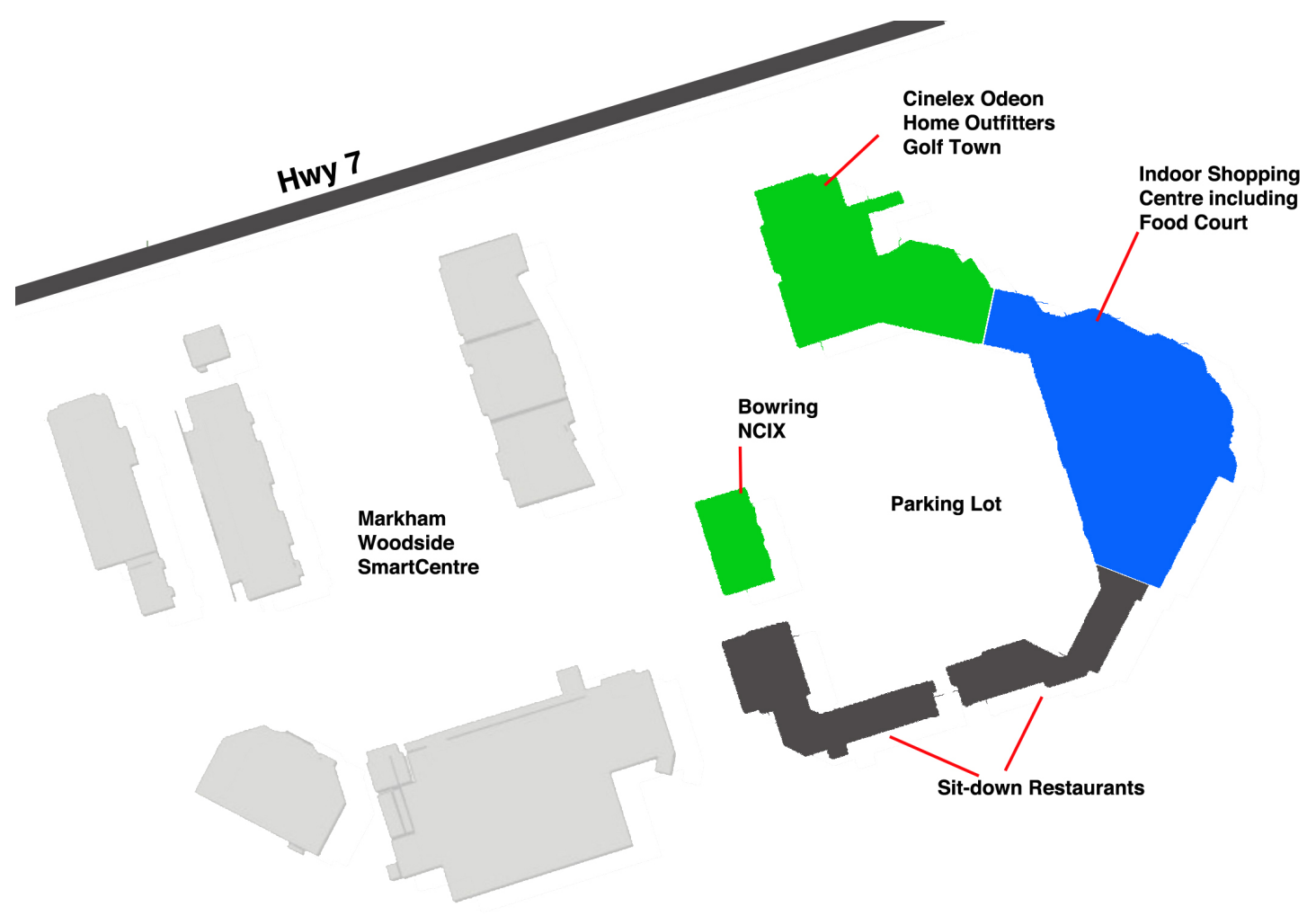

Figure 1. Diagram of First Markham Place \& adjacent power centre 


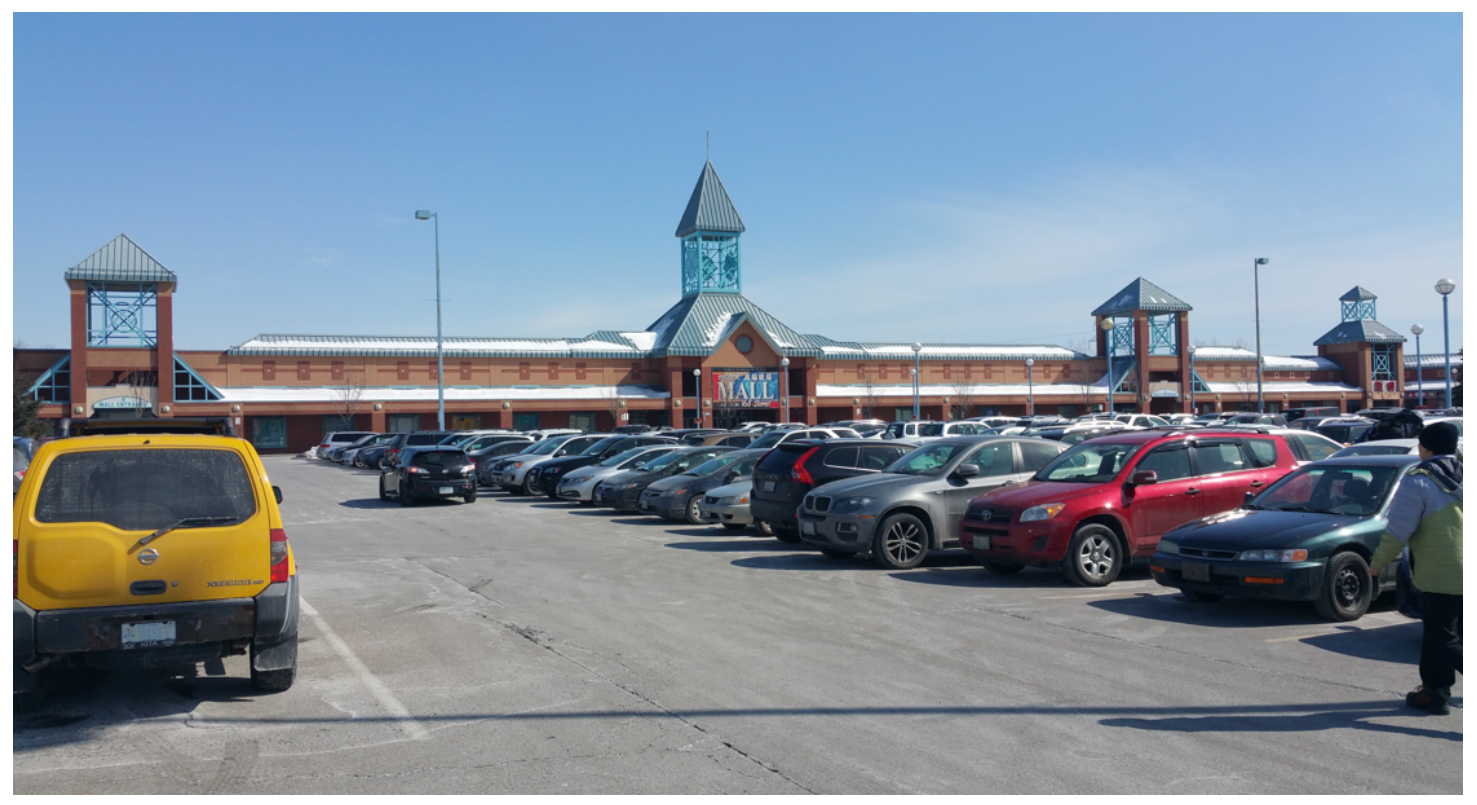

Figure 2. Front Entrance view of First Markham Place Shopping Centre

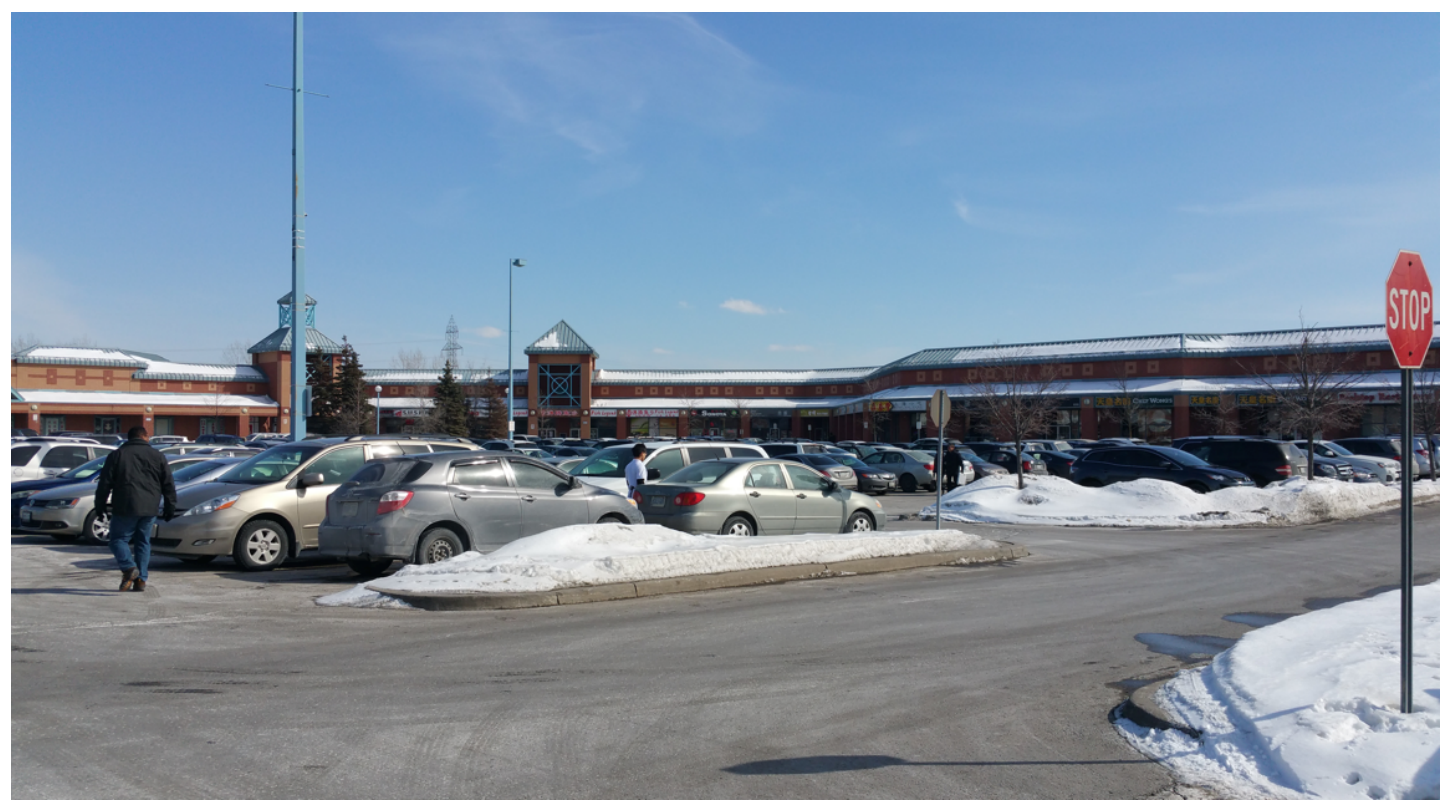

Figure 3. View of restaurants in the 'strip plaza' section of First Markham Place 


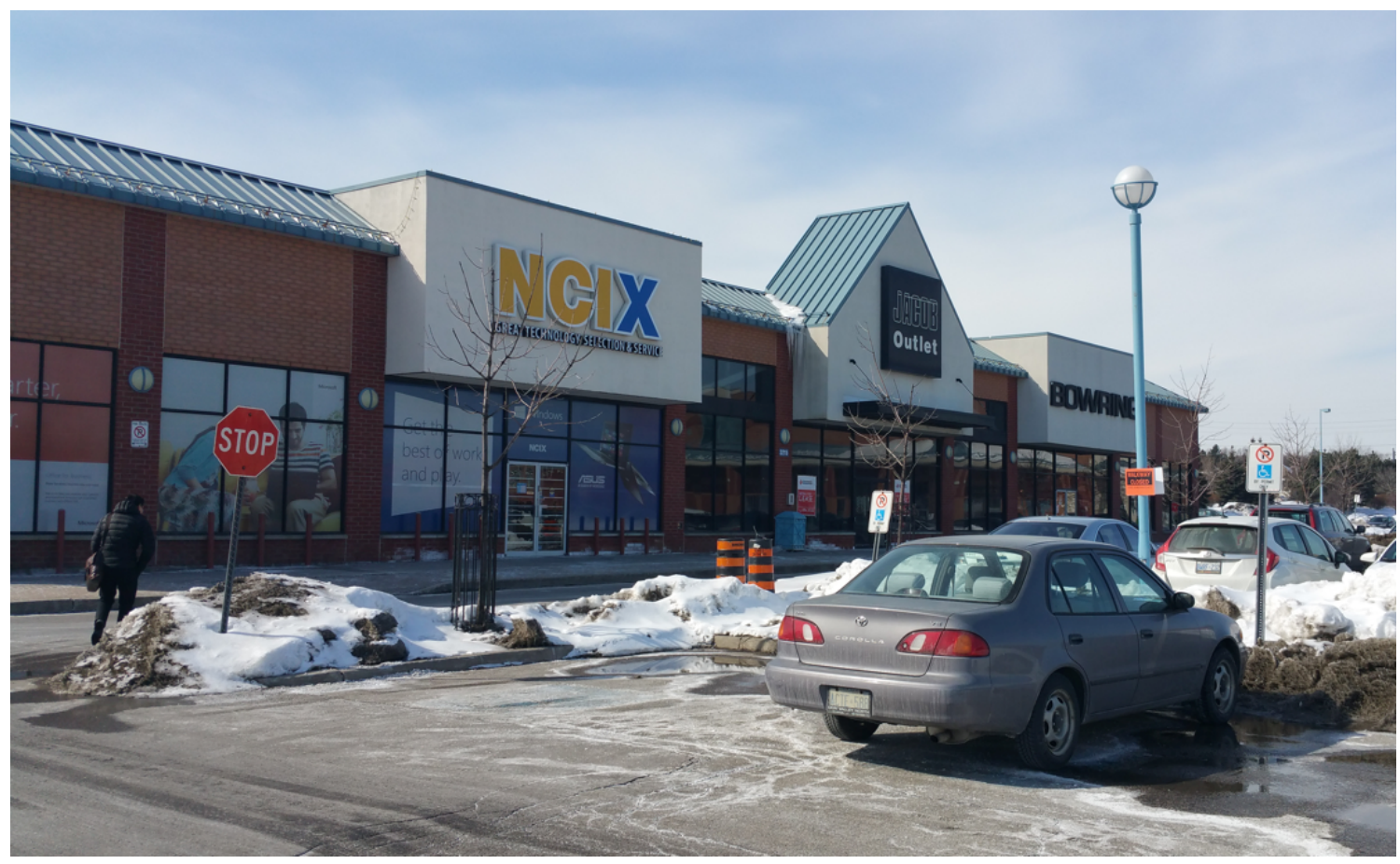

Figure 4. View of some of the 'mainstream' stores including NCIX, Bowring, and former Jacob Outlets

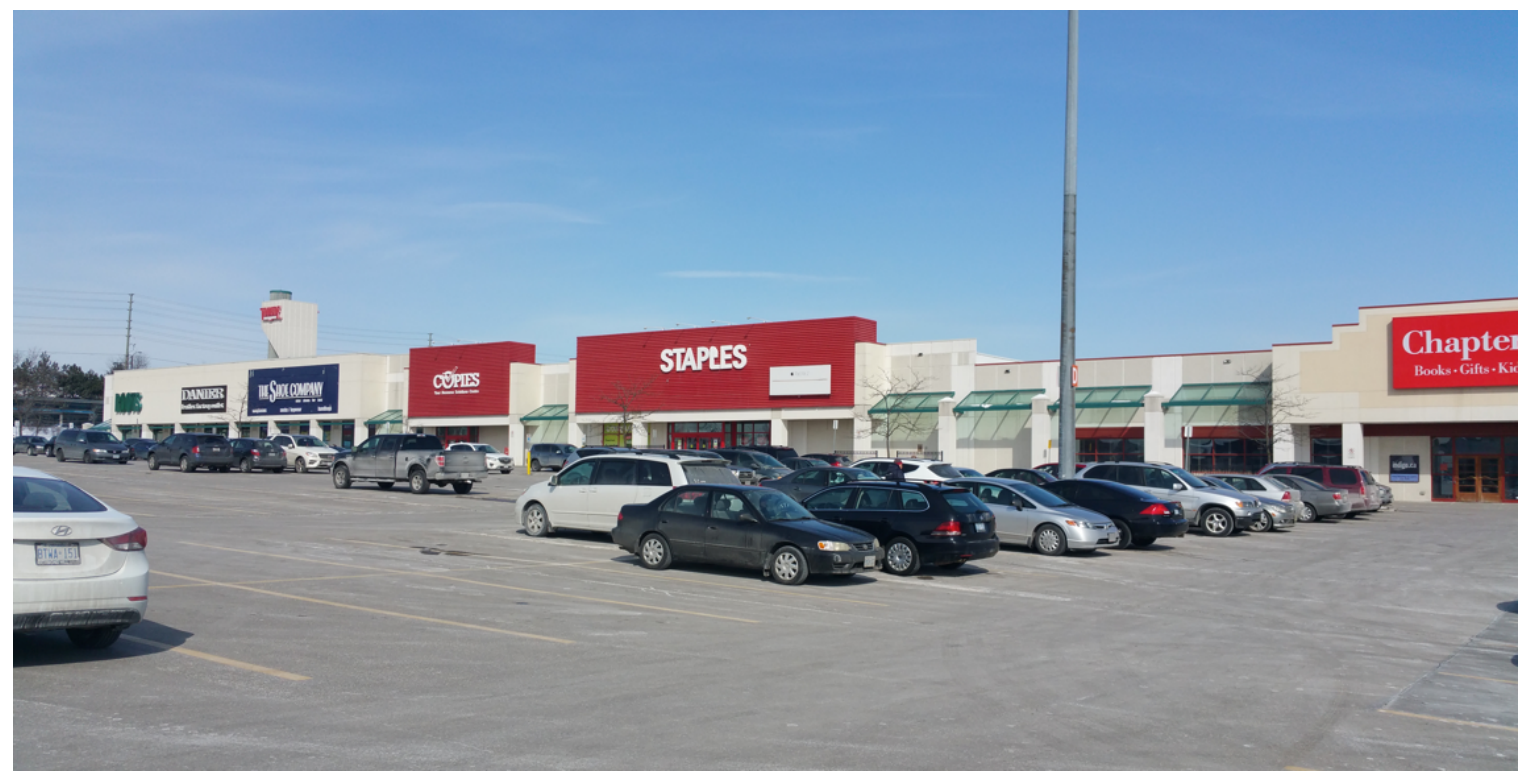

Figure 5. View of the adjacent 'Woodside' Smart Centre, with stores including Staples, Chapters, The Shoe Company, Roots Outlet, and more. 


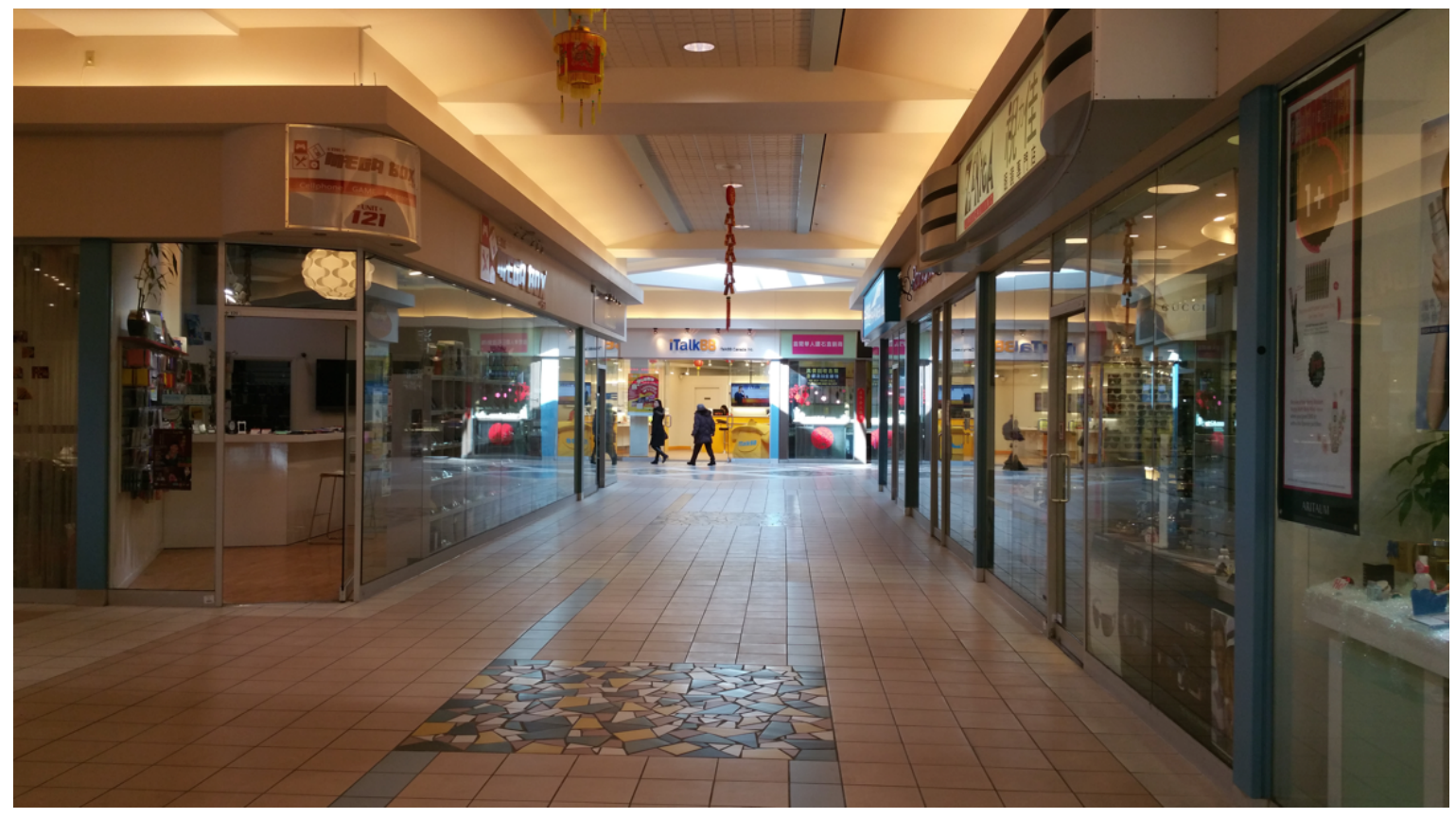

Figure 6. View of inside the shopping mall

\subsubsection{Data Collection}

For the purposes of this paper, a qualitative research approach was used in collecting primary data. The methodology includes a combination of ethnographic field observations and intercept field interviews. As the main objective of this paper is to understand how people use ethnic retail spaces, the meaning(s) people give the space, and the experience(s) of mall patrons, an ethnographic study is appropriate as it presents a "description of a people and/or their culture" (Neuman, 2003, p.423). Indeed, field research "requires directly talking with and observing the people being studied" (Neuman, 2003, p.421). Thus short, intercept style interviews were conducted at First Markham Place. Intercept style interviews take a convenience sampling approach, in which respondents are chosen if they are "easy to reach, convenient, or readily available. This sample type may be legitimate for...exploratory preliminary studies and some qualitative research studies when [the] purpose is something other than creating a 
representative sample" (Neuman, 2003, p.242). Interviews were conducted over the course of nine trips between January 12 and February 27, 2015. The trips were made during a variety of different times including weekdays and weekends, mornings, afternoons, and evenings. The trips generally lasted for one to two hours in which half the time was spent simply observing the study area. (See Figure $\mathbf{7}$ for a map of points I frequently visited to conduct my observations and interviews). Forty-five people and groups were interviewed, varying in age, gender, and background. The interviews were semi-structured and lasted two to five minutes depending on how long the respondent wanted to continue speaking to me and/or how much they had to say (See Appendix 1). Insights were also noted from a casual conversation conducted with the mall's property manager.

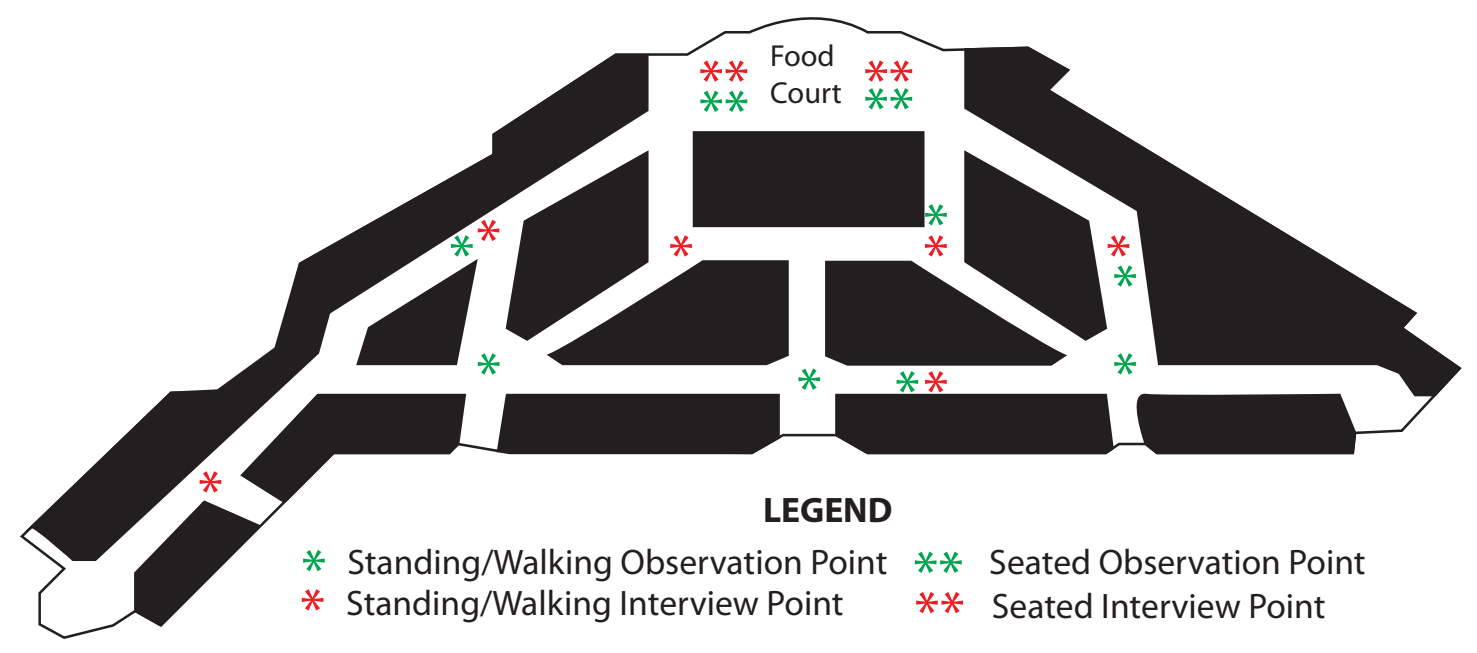

Figure 7. Figure Map of Indoor Shopping Centre and Frequent Observation / Interview Points. Note: this map does not represent an exhaustive map of everywhere I conducted my observations and interviews. Rather, it represents places I frequently, but not always, conducted my observations and interviews. 


\subsubsection{Analysis}

As with any ethnographic or field research study, analysis involves not only "describing people's lives and behaviour but also trying to infer the meaning of behaviour" (Neuman, 2003, p.424). This means I, the author, will to a certain extent need to use my "cultural knowledge" to make my analyses and inferences (Neuman, 2003). In regards to this, I will summarize my own personal background.

I was born in Toronto and raised in Markham. I am of Chinese descent and my parents emigrated here from Hong Kong almost forty years ago. Despite having spent my entire life in Canada, I am quite attuned with my cultural heritage. I am also very familiar with First Markham Place and have been regularly visiting the mall since I was young. However, all my findings will be based on observations I made during my field visits in which my primary focus was to conduct research.

The findings from the primary research will be analyzed using a 'narrative analysis' approach, commonly used for qualitative studies that look to "address the issue of 'who we are' as individual people...[or as] public narratives that link us to larger groups, communities, or nations...[they can] describe social forces that act on us" (Neuman, 2003, p.524). There are many types of 'narratives' that can be used in conducting and presenting narrative analysis. One type of narrative that will be used to form the basis of this paper's analysis section is 'narrative presentation' or 'story-telling'. This means that the analysis will be made up of "description, empathetic understanding, and interpretation" (Neuman, 2003, p.526). Indeed many of the most iconic pieces of planning or urban studies literature, like the works of Jane Jacobs and William Whyte, 
involve the author attempting to interpret and analyze field observations of how people used space. Andranovich \& Riposa writes that in applied urban research "field research holds a special status" and that "participant observation is basic to field work" (Andranovich \& Riposa, 1993, p.76). A key strategy they identified in carrying out this type of research is to "let your feelings help interpret your observations; [and] trust your intuition" (Andranovich \& Riposa, 1993, p.77).

The analysis will be split into the following three concepts as informed by the literature and themes that I observed: the ethnic mall as a public space; the ethnic mall as a manifestation of cultural preferences; and finally the ethnic mall in facilitating intercultural exchanges. Based on each concept, a 'narrative' will be presented in order to inductively uncover themes that explain and describe the role ethnic retail landscapes play in providing a community space and/or a sense of place. Narratives will be based on field observations and interview results. Interview 'counts' or 'numbers' may be used to help illustrate the narrative. However as mentioned earlier, since this paper does not utilize a quantitative research approach, it is important to note that the numbers themselves do not statistically prove any hypothesis. Rather, the interview results will be complemented by respondent quotes, pictures, and my own cultural understanding in order to present the full narrative. The narrative will be used as direct responses to questions, hypotheses, and concepts posed and identified by a variety of related literature on placemaking and ethnoburbs. In order to identify themes, a modest thematic coding analysis was performed in which important themes and similar 
responses were identified. The themes identified influenced the subtopics in the following Findings \& Analysis section (4.0 Chapter IV).

\subsubsection{Limitations}

One limitation to this study is that the sample is not equally varied in terms of age, gender, and background. This is due to the fact that a convenience method was utilized in choosing respondents. Though a general effort was put into interviewing a variety of people, no set quota was strictly adhered by. This decision was based on the qualitative nature of this study. Given the scope and time restrictions of this paper, it was determined that a perfectly varied sample is not required as the essence of the primary findings are the narratives and opinions of the respondents rather than numerical counts.

Another limitation is that while field research generally takes place over a longer period of time, this study was relatively modest. However, smaller field research is sometimes done in smaller specific sites like hair salons, schools, etc. (Neuman, 2003).

In addition, the scope and time restrictions of this project also mean that only one case study could be conducted. Thus, it is important one does not mistakenly misinterpret the discussion and mistakenly assume that everything discussed can be applied to all ethnic malls. Instead one should keep in mind the context of the case study and the narratives presented.

Finally the Chinese culture is a very extensive and complicated one. Like with any ethnocultural group, there is no single understanding of the culture. Therefore all 
narratives documented are based on the individual's personal understanding of the culture, and is influenced by a variety of factors including their own personal experiences, where in China or Asia their ancestors are from, how immersed they are in the culture, etc. 


\subsection{CHAPTER IV: Findings \& Analysis}

\subsection{ETHNIC RETAIL LANDSCAPES AS A PUBLIC SPACE}

This section analyzes First Markham Place as an example of how ethnic retail shopping centres can act as a public space. This is in response to the aforementioned lack of space in the suburbs, and discusses whether privately owned 'public' spaces can actually provide community space in a way traditional public spaces used to. This is especially important in ethnoburbs, where the suburban setting means that its citizens reportedly lack pubic space, and its demographics consists of ethnic minorities that have specific public space needs sometimes unmet by conventional public spaces (Galanaskis 2013). Thus this paper defines 'public spaces' not only as spaces designated and provided by the state as public spaces, but also the broader definition of it being any space that is open and accessible for anyone to use. This puts the focus not on public space, but rather the "concept of public life, which encompasses both private and public realms" (Banerjee, 2001, p.9).

\subsubsection{Are ethnic malls a good 'third place'?: 'Public life' and sociability}

In exploring whether or not First Markham Place acts as a good alternative to public space, I analyzed my field observations and interview results based on some of the characteristics Oldenburg identifies as being important to a good 'third place', as referenced in the above literature review. Indeed most mall patrons carry a reclusive attitude typically seen in most suburban mall settings, like the disinclination to speak to strangers on a regular basis. Still, it is apparent that the relatively smaller and closer-knit 
ethnic community the mall mostly caters and acts as a hub to is able to at least encourage more social interactions and personal relationships between both patrons and storekeepers, and between patrons themselves, relative to conventional suburban malls.

\subsubsection{Accessibility, accommodation, and 'the regulars'}

Oldenburg believes that a third place is one that is accessible and accommodating. This means a place that is not only physically accessible, but one where a person can feel welcomed by regulars and/or acquaintances without coordinating a meet up beforehand (Oldenburg, 1989). In terms of accessibility First Markham Place, like most shopping malls, is open to anyone and is arguably more accessible than the coffeehouses, pubs, cafes, and taverns mentioned in Oldenburg's The Great Good Place. That is because one does not have to be a paying customer to use the space. Indeed I was able to sit in the food court to do my observations without purchasing any food or drinks. On most of my visits I observed at least one person reading the newspaper at the tables without a noticeable food purchase, or any other purchase for that matter except perhaps the paper. However, when it comes to expecting there be acquaintances there for one to talk to, First Markham Place mostly misses the mark. For example during my field visits, I observed that people sitting at the food court chatting were generally talking to people that they came and left the food court with. It is likely that these groups of people came to the mall together and/or decided beforehand to meet up, as there was usually no evidence of them 'running into' 
each other by chance through my observations. For example when I interviewed groups of people, most respondents seemed to have purposely visited the mall with the people they were with, whether they be coworkers grabbing lunch together or family members doing errands.

That said, while not frequent, on occasion during my field visits I saw and heard patrons greet each other in a way that implied they 'ran into' each other by chance. One respondent of Chinese descent told me that even though it is not a regular occurrence, she "would not be surprised if I saw a person I knew here because a lot of my friends that are also Chinese live in the same area" (Respondent AC, personal communication, January 21,2015$)$. A time where this may be especially true is in the morning. On both of my early morning visits, I observed seniors practicing tai chi at the mall. While there is a large group of people in uniforms doing tai chi in the food court, which the manager tells me is part of a large club consisting of three hundred members (Property Manager personal communication, December 17, 2014), there were several much smaller groups in the hallways also practicing tai chi. One elderly lady told me that the group she does tai chi with are people she met at the mall and had not known before. She also said that on an average morning she would "say hi to eighteen to twenty people" (Respondent $\mathrm{BO}$, personal communication, February 27, 2015) all of whom she met just from regularly going to the mall every morning. Meanwhile another respondent, one that claims he regularly "eats breakfast in the food court every morning", was greeted by a man in uniform during my interview with him, and he told me he had also met him from just being a regular (Respondent BO, personal communication, February 27, 2015). 
Perhaps more common is the ability for patrons to personally get to know storekeepers. Unlike what critics say about it being difficult in conventional suburban malls to form personal relationships with storekeepers (Scharoun, 2012; Oldenburg, 1989), it is noticeably different in the case of First Markham Place. Nine of the respondents I interviewed mentioned knowing the storekeepers of the stores they often visit. Examples mentioned include not only stores in which it is normal to know the workers like at a hair salon, but also health supplement stores, herbal and dried seafood stores, and optical stores. Reasons stated regarding how they got to know the storekeepers include both being a regular of the store, but also through personal connections. One respondent told me "I have been going to the same optician since I was ten years old"' (Respondent AM, personal communication, January 24, 2014).

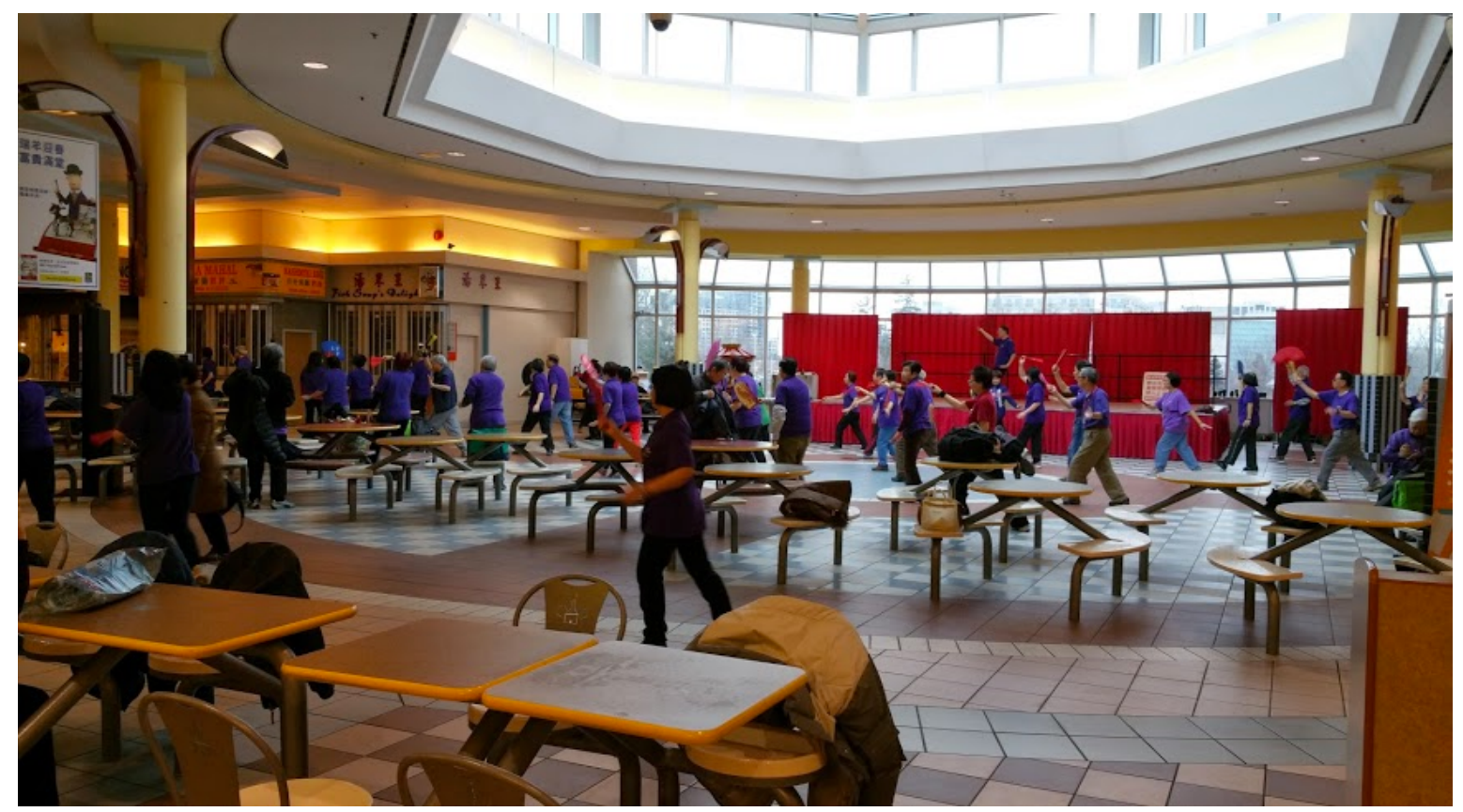

Figure 8. View of people doing a traditional 'fan dance' exercise at 9:30 in the morning 

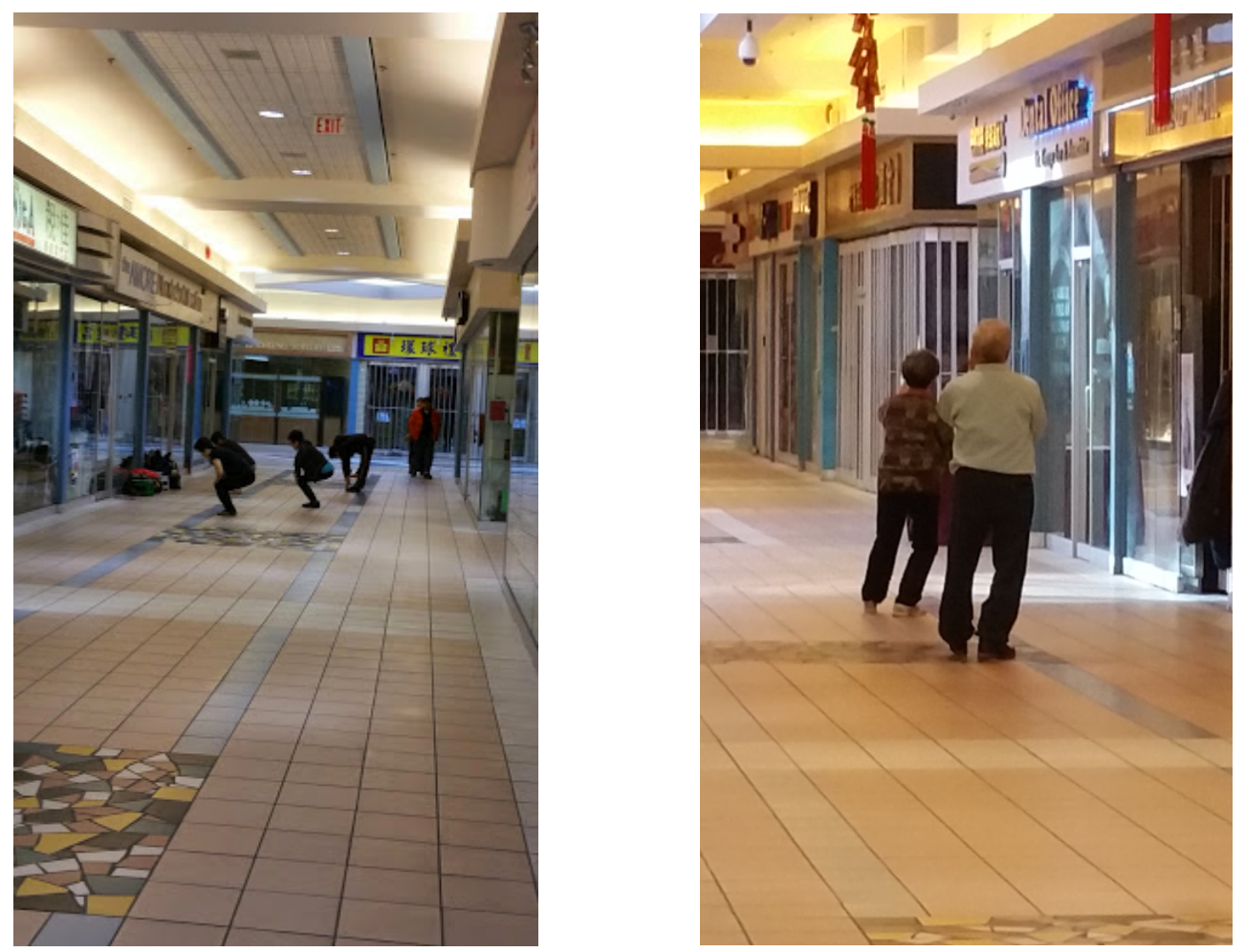

Figure 9. View of independent groups not affiliated with the social club doing tai chi in the morning

The relationships here between mall regulars in the morning and also storekeepers and their patrons suggest that unlike in conventional shopping malls (Scharoun, 2012; Oldenburg, 1989), personal relationships and a 'public life' is more able to occur within ethnic shopping centres. Perhaps the reason for this is because ethnic malls serve a more specific community in which social networks are more likely to get entangled with retail services. The fact that most stores in the mall are independently owned and not large chains may also mean that storeowners hire fewer employees compared to large retailers with more employees doing shorter shifts (Meyer, 2013; Stimson, n.d.). Finally, these relationships may also be due to innate connections between two people of similar cultural background, though this will be discussed in more detail in a following section of this paper. 


\subsubsection{Is conversation the main activity?}

A good public space is not only about the physical space itself but the relationships and social interactions that occur there (Oldenburg, 1989; Banjee, 2001). Perhaps for this reason, Oldenburg says that in a good 'third place', conversation should be the main activity (Oldenburg, 1989). For the most part it does not seem like that is the main purpose patrons visit First Markham Place. Twenty-two of the respondents I interviewed mentioned only visiting First Markham Place when they had something specific they wanted to buy or if they required a specific service. In contrast only one respondent was at the mall because it was a place where she could sit and have a conversation with her friend (Respondent BE, personal communication, February 16, 2015). That said, while it seems like very few patrons go to First Markham Place for the sole purpose of needing a place to have a conversation, the shopping centre's food court nonetheless provides a good venue to do so. One group of people observed spent at least an hour chatting with each other in the food court. The group consisted of around sixteen people, ten of which were middle aged and another six youths. When I went to interview one of them, the respondent told me they "are here for a late lunch after coming from the movies" (Respondent AZ, personal communication, February 27, 2015). Everyone in their group had finished their lunch as no one was eating; yet they were comfortable sitting in the food court chatting two hours after first arriving at the food court. Indeed, seeing people continue conversations long after meals were eaten was a common site during my field observations. Despite what Oldenburg noticed about 
shopping mall food courts as being places "designed for high volume and fast turnover" (Oldenburg, 1989, p.121), these observations show that shopping mall food courts have the potential to be places where people can enjoy long conversations after, before, or even without a meal.

\subsubsection{A venue for optional activities}

Though it is important that public spaces, or any space hoping to act as an alternative to public spaces, help facilitate and accommodate the social interactions and 'public life' mentioned by Oldenburg, public spaces can be more than just good 'third places'. Public spaces should allow for a variety of other uses as well. Project for Public Spaces, a non-profit organization dedicated to expanding the work of William Whyte's Social Life of Small Urban Spaces, supports the idea that 'sociability' is just one of the attributes of a great place. Indeed, having a variety of 'uses and activities' is another key attribute and some of the activities the organization listed as being ones that can take place in a 'good' public space include "reading, relaxing, and eating" (Project for Public Spaces, n.d., Figure.1). All these activities are ones in which conversation is not necessarily the focus.

In order to determine the appeal of First Markham Place as a venue for various activities beyond consumption, the discussion below identifies several activities I observed or were mentioned in my field interviews aside from the aforementioned practice of tai chi. Furthermore, all the activities I will discuss are those not considered 'necessary' but 'optional', as I referenced earlier from Gehl's works. (See Appendix 2). 
In the context of ethnic malls as alternatives to public space, the prevalence of 'optional' activity reflects the space's appeal as a place for non-consumption leisure. From the discussion below, it appears that the mall is able to provide spaces for people to enjoy aside from being simply places to purchase goods and services. However for many people, much of the mall's appeal still lies with the quality and diversity of the goods and services offered at the mall.

\subsubsection{Window-shopping}

An activity Jan Gehl identifies as being relatively optional is window-shopping (Gehl et al, 2006; as quoted in Gehl \& Svarre, 2013). This is a common activity seen in many shopping centres and districts. It is significant in the discussion of public spaces in that it represents an activity done at shopping malls exclusively for enjoyment or pleasure. While purchasing foods and services can be enjoyable, it may be practical as well. However, optional activities like window-shopping are done only for enjoyment. In terms of window-shopping, First Markham Place does not appear to be a space in which this optional activity of enjoyment is conducted. As mentioned earlier, twenty-two of the respondents said that they always go to First Markham Place for the purposes of purchasing a specific good or service and rarely window-shopped, as opposed to four people that said they do come to First Markham Place to window-shop. When asked why they did not go to First Markham Place to window shop, it seems like the size of the

mall plays a part as well. Four respondents said that even though they do go to Chinese 
malls to window shop, they are more likely to do so at Pacific Mall ${ }^{2}$ because it is larger and there are more things to look at. This hints that for the seemingly 'optional' activity of window-shopping, some practical factors like the diversity of products and consumption potential still plays a part.

\subsubsection{Studying and Reading}

Another 'optional' activity mentioned by Gehl, as well as other academics, that can take place in a public space is sitting to read (Gehl et al, 2006; as quoted in Gehl \& Svarre, 2013; Project for Pubic Spaces, n.d.). This was an activity that I observed on several of my field visits. As mentioned earlier, the sight of middle-aged to elderly patrons reading the newspaper or magazines was quite common. However, I also observed a number of younger students studying at the food court. One respondent said she was studying at First Markham Place because her mother had previously come with her to get her glasses fixed, and that she asked her mother to leave her there to study for a bit before getting picked up later (Respondent $A Q$, personal communication, January 25,2015$)$. She also said that the experience of studying at the food court was a good one because the large open space made her feel comfortable. In this situation, even though the initial reason for choosing First Markham Place as a place to study was out of convenience, the fact that she told her mother to leave her there so she could study showed the intention of wanting to study at the shopping mall.

\footnotetext{
${ }^{2}$ A large Asian, primarily Chinese-focused shopping centre located in Markham at the intersection of Kennedy Road and Steeles Avenue. Within the mall is 500 retail stores covering approximately 270,000 square feet of space. Stores within Pacific Mall are overall smaller and the inside of the mall features very high ceiling and exposed beams with an 'unfinished' ceiling.
} 


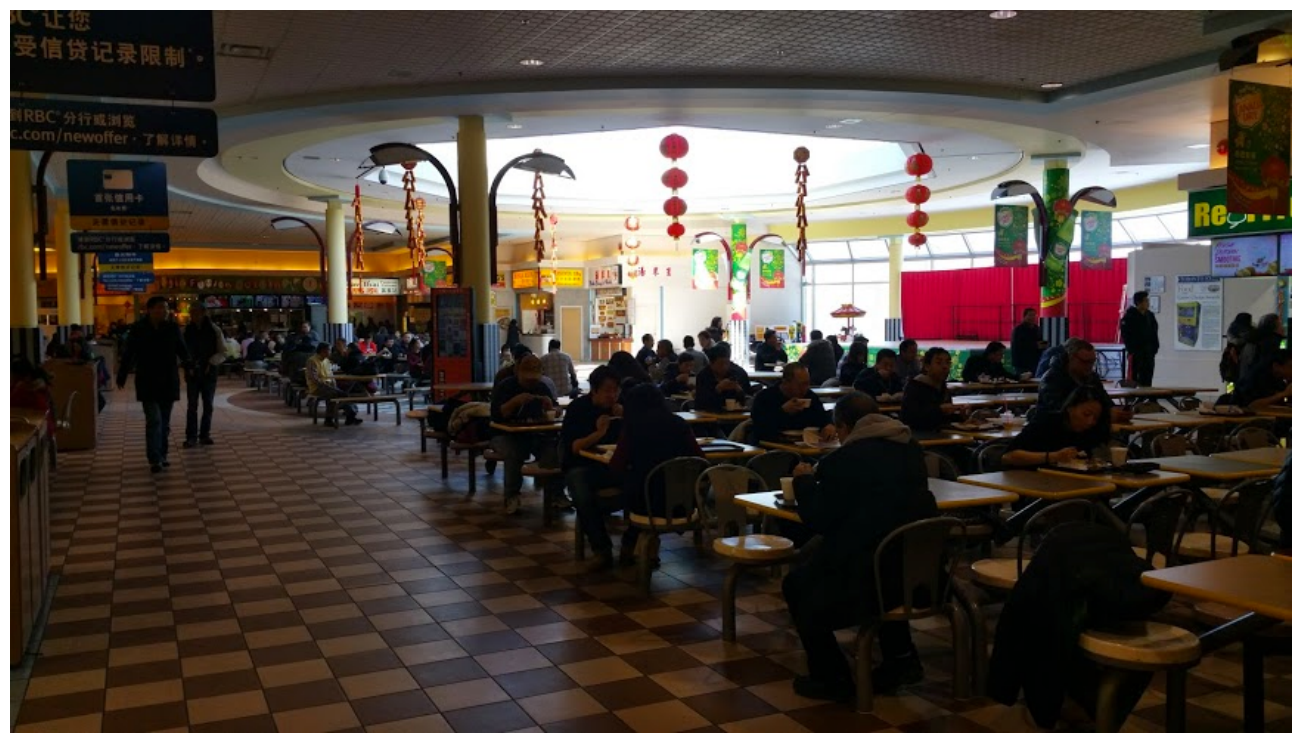

Figure 10 View of the food court

During another visit on Family Day, I observed a pair of friends that purposely met up and drove to the shopping mall to study.

"Most things are closed and we prefer studying outside of home, so we decided to come here. So far it's been pretty good. It's not any noisier than a Starbucks, and I generally like having a bit of activity and white noise. I normally like to think of my home as a place to relax. Also, I like it here because there are always seats" (Respondent BC, personal communication, February 16, 2015).

From these examples, it is apparent that shopping malls can be an attractive place for people to read and/or get work done. Like coffee shops or cafes, it provides a good amount of social stimulation that some find desirable for getting work done, but is even more accessible in that one does not need to be a paying customer. Furthermore it represents a comfortable environment where one can feel safe enough to concentrate their thoughts on their work.

By providing a venue for people to simply enjoy, and to visit just for the sake of 
being there, ethnic shopping malls like First Markham Place are capable of being a quality public space like the parks and public squares of traditional city centres.

\subsection{3 'SENSE OF PLACE’ THROUGH CULTURAL ATTRIBUTES}

In response to criticisms that suburbs and suburban indoor shopping malls suffer from a lack of sense of place, scholars and retail developers alike have looked at the placemaking potential of lifestyle centres (Pride \& Ferrell, 2010; Ross, 2007; Laniado, 2005; Gillem, 2009), hoping to create more appealing shopping environments for shoppers. By taking aesthetic cues from traditional American main streets, it is meant to evoke North Americans with their historical roots. However, efforts have been met with varying success, with some asserting that design features are not enough. Indeed Project for Public Spaces president Fred Kent argued, "a sense of place is more important than the design itself" ("An urbanist says...", 2000, para.1). As discussed in the previous section, social interactions are a key part of placemaking, and in that aspect indoor shopping malls have the potential to be good public spaces. Another key aspect to placemaking however is related to one's more personal connections to their self-identity.

Indeed, "despite the many studies using the concepts of place identity and place attachment, few have provided a clear and theoretically driven account of the relationship between place and identity" (Twigger-Ross \& Uzzell, 1996, p.26). However, one type of identity that is perhaps most tangible to understand is one's ethnic and cultural background. As mentioned in Chapter I of this paper, the tendency to self- 
identify with and desire a strong connection to one's ethnic heritage and cultural community is a key factor behind the formation of ethnoburbs (Qadeer et al., 2010; Glazer and Moynihan, 1963; Wen, 2009). In this regard ethnoburbs provide a clear 'sense of place' to the many people that freely choose to live in them or visit its institutions. It is therefore worth studying whether this 'sense of place' is present specifically within ethnic malls as well, a key hub within ethnoburbs. Indeed, Lo writes, "geography entails meanings consumers attach to sites of consumption" (Lo, 2009, p.395).

\subsubsection{Cultural preferences for ethnic goods \& services and its significance}

The availability of ethnic specific goods and services has long been one of the main pulls for ethnic minorities into ethnoburbs as discussed earlier in the literature review. While the desire for ethnic goods and services may appear to be just the result of ones personal taste, when aligned with one's cultural and ethnic background it may represent a more innate appeal related to one's self-identify. Indeed, past studies have discussed the "relationship between ethnic identity, consumer culture, and shopping behavior" (Lo, 2009, p.395). The following section discusses cultural preferences mall patrons have for goods and services that align to their own culture and/or is targeted to co-ethnics, and the significance that has in providing a sense of place. It argues that such goods and services can make ethnic malls attractive because of the familiarity it provides, thus creating a sense of place for mall patrons. 
When surveying patrons of First Markham Place, the most common purpose in visiting First Markham Place was to purchase food. Twenty-one of the forty-five respondents identified purchasing food as a main reason why they like to visit First Markham Place. While five respondents stated that they like getting food at First Markham Place because it is convenient for them, five respondents of Asian ethnicity also stated that they preferred Asian food. One respondent that moved to Canada from Hong Kong when she was two years old said

"When it comes to food, I much prefer Asian food. Not only is it cheaper and a better 'bang for the buck', but I just like the taste and variety of Asian food more. Sometimes if my Asian friends suggest going to a non-Asian restaurant to eat, I decide to skip eating with them or I would try to convince them to go somewhere else" (Respondent AC, personal communication, January 21, 2015).

Likewise, another respondent also mentioned the perception of Asian food being healthier (Respondent AM, personal communication, January 24, 2015). Also interesting to note is that three respondents mentioned they were especially likely to visit the sitdown restaurants outside of the mall when they are with family, and that they are most likely to eat Asian food when they are with their family. This may imply that as an entire family, the connection between ethnic minorities and their ethnic backgrounds is stronger. Furthermore, as all three of the respondents were either born in Canada or immigrated to Canada as a child, there is a possibility that older family members that moved to Canada at a later stage in life find the connection even stronger.

Aside from food stores, another commonly mentioned purpose for visiting First Markham Place was to go to the optical stores. Eight respondents mentioned they visit 
First Markham Place to buy glasses or get their glasses fixed. The demand for Chinese optical stores amongst the Chinese population is apparent when one looks at the mall directory. Eleven (6\%) of the mall's 180 stores are optical stores, in comparison to one $(0.67 \%)$ of the 150 stores at Markville Shopping Centre, the closest conventional mall. This is also true at Pacific Mall where nineteen (4\%) of the mall's 450 stores are optical stores. While the brands sold at these optical stores are mainstream brands one would find at a conventional shopping centre, respondents said they preferred going to Chinese stores because they were perceived to be cheaper, and that the service was believed to be better. Two middle-aged respondents said that it was more comfortable being able to speak Chinese (Respondent AB, personal communication, January 12 , 2015). However, seven of these eight respondents had lived in Canada for at least 15 years, four of which were either born in Canada or came at a young age. Therefore, the preference to visit Chinese optical stores was not because of necessity due to language barriers. This perhaps implies an innate preference to be served by someone of similar cultural backgrounds when it comes to services or consumption that requires more personalized attention. Indeed, three respondents of Chinese background identified that their dentist was also located at the mall, while another three got their haircuts at the mall. All three of these services are ones where more personal relationships are expected between the customer and the business practitioners, especially the latter two.

\subsubsection{Stores catering to cultural practices and traditions}

A side note that reveals itself from the popularity of optical stores is the perceived 
notion that Chinese optical stores are cheaper, even if it is for products available elsewhere. If true, this may point to yet another contrast with what literature has often criticized about the lack of community and 'place' within conventional shopping malls. As mentioned in 2.0 Chapter II, Scharoun believes that feelings of community are absent from the overly controlled suburban malls and that the symbiotic relationship between customers and storekeepers no longer exists (Scharoun, 2012). In demonstrating this she makes references to how "all of the merchants agree to maintain regular hours and carefully control their signage and sales pitches - techniques which avoid the appearance of haphazard or eccentric individualism" (Scharoun, 2012, p.67). Yet, a number of my respondents identified better deals, not only at optical stores but also at clothing and health supplement stores as well. These deals represent not only a different sales strategy but also a more personalized service for customers sometimes based on personal relationships. It represents an example of how customers may feel like they 'belong' in the commercial environment, and that more than their money is wanted. The following discussion argues that the symbiotic relationship found in ethnic malls between patrons and storekeepers not found in conventional suburban malls, whether it be closer relationships to more personalized services, create yet another sense of community unique to these retail landscapes.

An example of the aforementioned store 'flexibility' that I observed was in the morning where I always saw one food court stall open before any of the other food stalls. The stall specializes in Hong Kong-style food and serves breakfast items popularly found in cha chaan tengs (茶餐廳), a popular diner-like restaurant format 
known in Hong Kong for its neighbourhood appeal and often considered a cultural icon.

One respondent said

"I eat here morning because they have the cheapest breakfast in the city! I believe that eating breakfast is a good habit to get into and l've been doing it since I was young back in Hong Kong where I would go eat at the neighbourhood cha chaan teng every morning" (Respondent BJ, personal communication, February 27, 2015).

He also mentioned enjoying being able to watch live Hong Kong news as he ate, in reference to a TV monitor set up above the food stall that plays a Hong Kong news channel all day long.

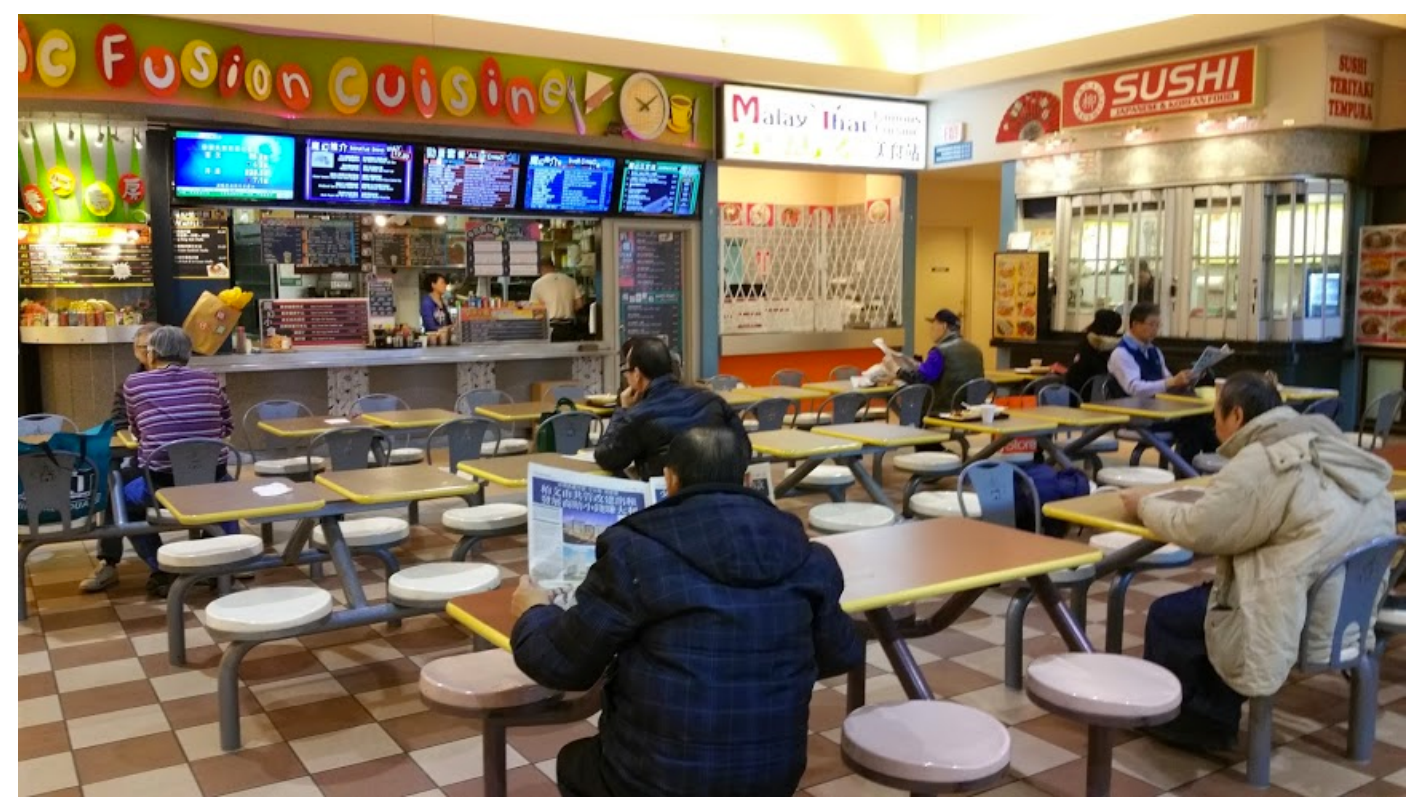

Figure 11. People eating breakfast and reading the newspaper while facing a TV monitor, playing live Hong Kong news, set up above the only food stall open in the morning

Another example of store flexibility was observed on Chinese New Years eve when the mall's flower shop had set up a table selling 'Chinese New Year' flowers, one of several stores opened that night past regular mall hours to cater to mall patrons 
visiting the mall to watch the countdown show. In parts of China, 'walking the flower market' (行花市) or 'walking the year-night' (行年宵) is a tradition on New Years Eve. Though there was no 'flower market', several stores including the flower shop had makeshift booths to help mall patrons simulate the experience. Though it is not uncommon in conventional malls for certain businesses to open outside regular mall hours, the business practices between the independently owned stores and the mall's patrons represent a more symbiotic relationship catering to cultural preferences. Furthermore, it is in stark contrast to Oldenburg's observations that within suburban shopping malls, "what's there is rigid and inflexible" (Oldenburg, 1989, p.120).

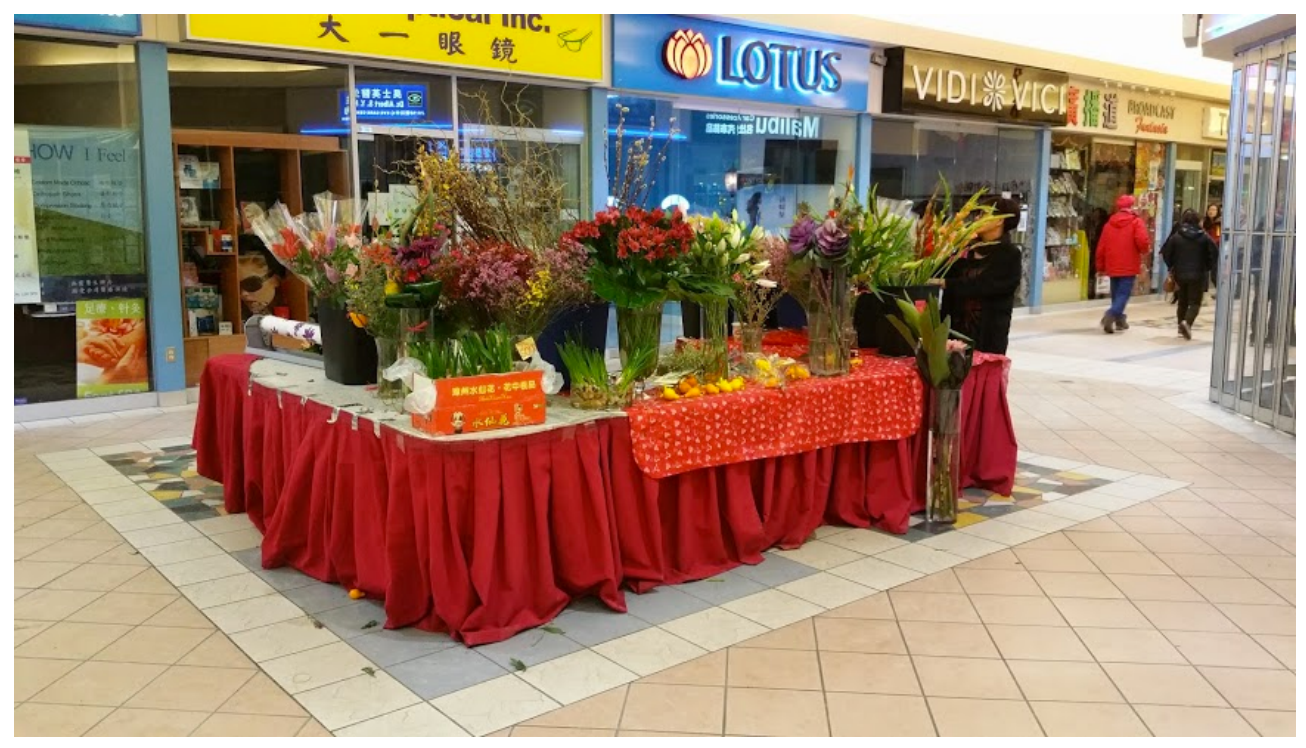

Figure 12. A makeshift booth selling flowers on Chinese New Years Eve 


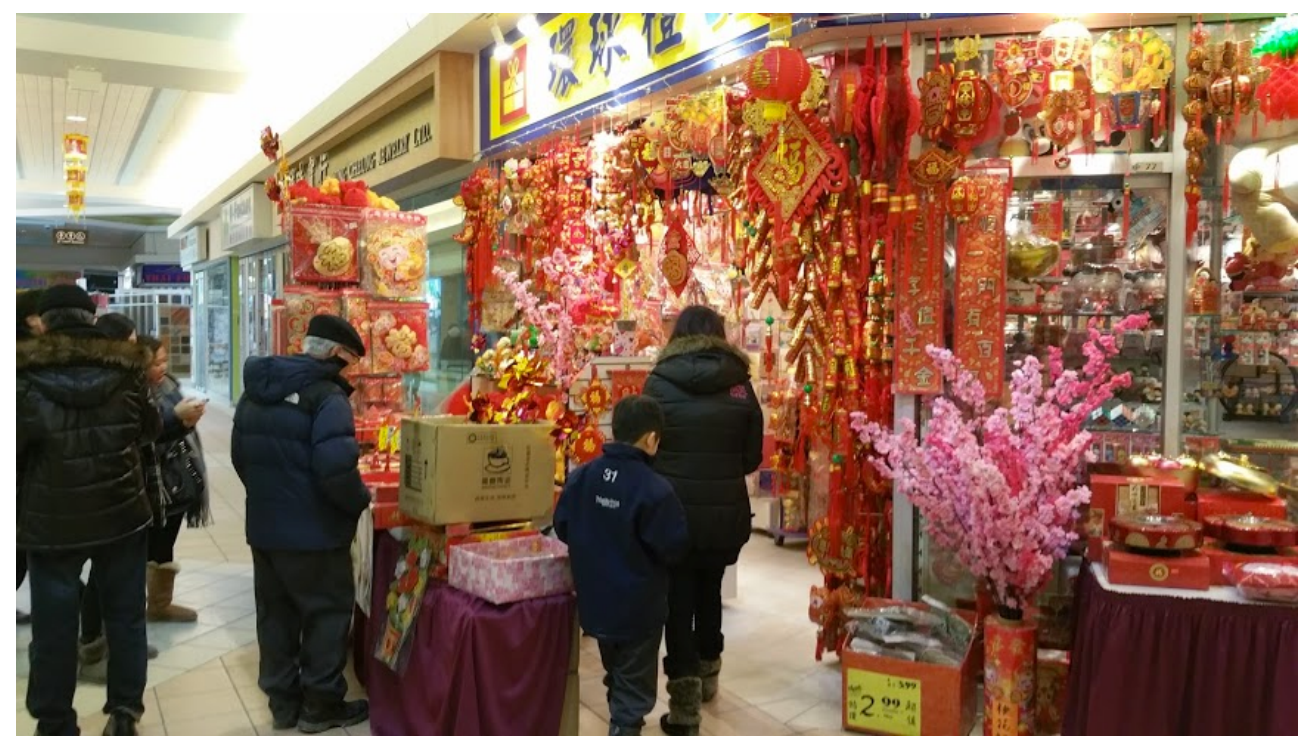

Figure 13. One of a few stores opened past regular hours on Chinese New Years Eve selling lucky Chinese New Year items

With all this in mind, it appears that ethnic malls are able to foster a sense of place and belonging not only by satisfying the consumption preferences of those that identify with their cultural background, but by providing a relationship between shopkeepers and mall patrons not seen in conventional shopping malls. Indeed, Liu et al., writes, "merchants [of ethnic businesses] play an important role in developing social ties within a community" (Liu, et al., 2014, p.571).

\subsubsection{Innate preferences for co-ethnic environments}

As mentioned in 2.0 Chapter II, literature on ethnoburbs has cited the natural tendency to be amongst co-ethnics as a reason behind the formation of ethnic enclaves. This section looks to see if this innate desire is manifested in the way ethnic minorities experience ethnic malls, again through the study of First Markham Place and its patrons. The findings seem to reveal that ethnic suburban malls are able to provide a sense of place by satisfying innate desires to connect to ones own culture. However, it 
also reveals that it varies not only by person, but also time.

Interviews with respondents have shown that some mall patrons visit First Markham Place for what appears to be an inherent desire to be in a co-ethnic environment. One respondent said the following

"I like coming to First Markham Place because it feels more familiar. I feel comfortable being here because it reminds me of Hong Kong. The style of the stores, the people...it all feels very familiar." (Respondent AA, personal communication, January 12, 2015)

He stated that he often comes to First Markham Place without the intention of buying anything. However, he said that he does not go to conventional malls without a purpose or to just enjoy the environment. Likewise another pair of respondents said the same thing, that "if I wanted to shop, I'd go to a mainstream mall. Whenever I am here, it is really just to chill' (Respondent BE, personal communication, February 16, 2015).

However, this tendency to go to First Markham Place just for the environment does not seem to be true for most people. As stated earlier, twenty-two respondents mentioned that they only come to First Markham Place if they had a purpose. Eight respondents mentioned that they are more likely to go to another mall to window shop as the items there interested them more. Three of these eight respondents said that they preferred conventional malls, including one 25-year-old Canadian-born-Chinese male that said, "Nothing here really suits my interest. The clothing here does not really suit my personal style. Maybe for females the clothing here might be more fitting" (Respondent AE, personal communication, January 21, 2015). Another respondent said, "I prefer Yorkdale Mall because there are more brand-name clothing and items. 
There are also more things to look at because the mall is larger" (Respondent AO, personal communication, January 25,2015$)$. Thus this suggests that for many people when deciding what mall to visit, the opportunity purchase items that are of more interesting to them outweigh the need to be in an environment surrounded by co-ethnic people.

The innate desire to connect to one's own cultural identify however was most apparent in field visits during the mall's Chinese New Year events. Indeed, Pascoe (1992) writes that participation in rituals is one of three steps of placemaking for immigrants taking up residence in a foreign place (as quoted in Sandercock, 2003). One respondent interviewed said, "I came for the atmosphere. I generally try to find things to do every Chinese New Years eve so this year I called in [to the radio station hosting the Chinese New Year countdown show] to try to win tickets" (Respondent BL, personal communication, February 18, 2015). While some respondents interviewed on Chinese New Years Eve was at the mall specifically for the countdown show and/or had tickets that allowed them to sit closer to the stage, many came just for the atmosphere. One respondent that came with her children said "we finished dinner early so we decided to drive here and walk around since it is Chinese New Year" (Respondent BO, personal communication, February 18, 2015). Likewise another family interviewed, this time a Canadian-born-Chinese couple and their son, said "we try to go to a Chinese mall every year for the atmosphere. It's fun for my son and it's also a way to expose him to our culture" (Respondent BP, personal communication, February 18, 2015). This is a classic example of episodic visiting and/or memory, which is said to have a connection to place 
making (Wen, 2015).

The sentiment of using cultural events to connect second or third generation Chinese Canadians to their cultural heritage was observed during another visit when the mall held its Chinese New Year Lion Dance event. The food court that particular day was especially busy and packed with families with young children. While not exclusively a 'children's event', the organizers seemed aware of the large number of children present and targeted its dialogue towards them. Most children looked to be of East Asian descent though the presence of interracial families and multiracial children was also apparent. One respondent that was present with her family including several mixed grandchildren said

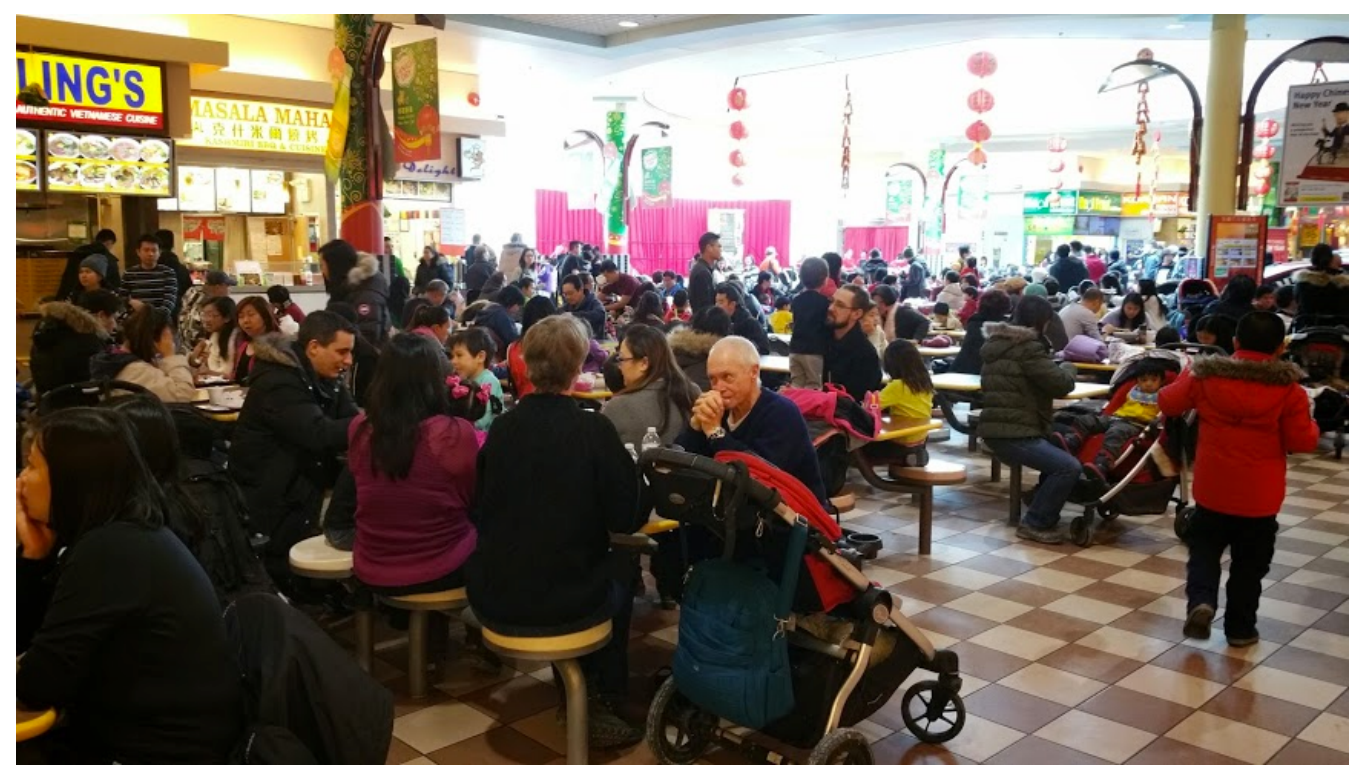

Figure 14. The food court during the Lion Dance performance, with a noticeably larger presence of children and strollers than on an average day. 


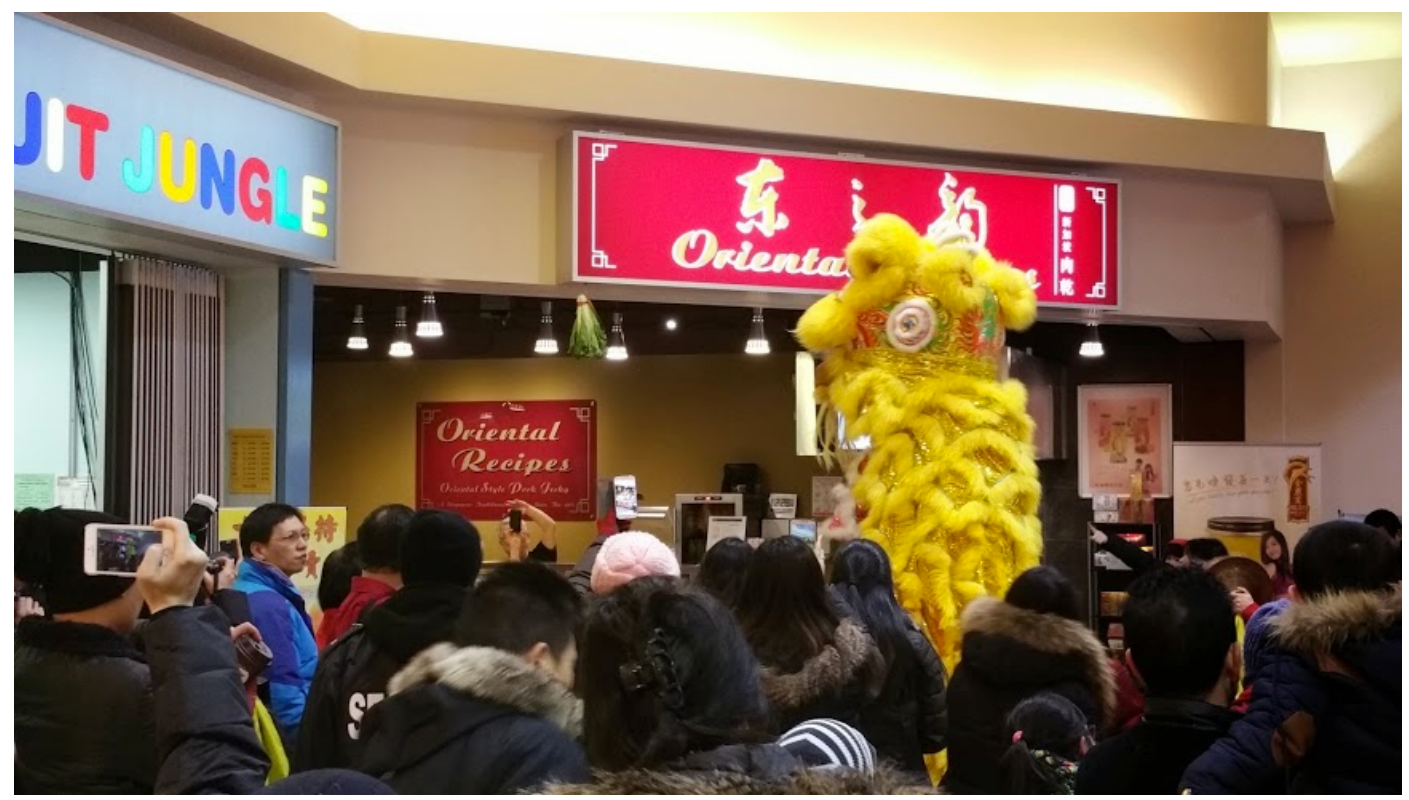

Figure 15. 'Lion Dancers' perform the 'plucking the green' ritual, a tradition considered lucky for the storeowner. Lettuce is hung from any store that wanted to participate.

"I saw them advertise this event in the newspaper and I thought it would be a fun way to expose my grandchildren to Chinese culture. A lot of other mall and restaurants have lion dance performances as well but the large open space of the mall makes taking care of the children easier. Also, only at Chinese malls can I show them the tradition of 'plucking the green' (採青)" (Respondent BR, personal communication, February 22, 2015). ${ }^{3}$

While the tendency to visit ethnic malls for an innate need to self-identify with one's cultural heritage varies by person and scenario, the interviews and observations done for this paper suggests that the potential in which ethnics malls can facilitate this most certainly exists. Indeed, factors that come to play are highly varied, including time of year, different family situations, the type of entertain that is sought after, etc.

\footnotetext{
3 A Chinese New Year tradition where Lion Dancers pretend to eat vegetables hung outside storefronts with red packets attached that is supposed to bring luck to storeowners and businesses.
} 


\subsection{INTERCULTURAL EXCHANGES}

So far this paper has discussed to what extent ethnic malls as well as suburban indoor shopping centres in general are able to provide an alternative to public space. It has also discussed the way in which various cultural characteristics are, and in some cases are not, able to provide an added sense of place for patrons belonging to the shopping centre's primary demographic. This section however will discuss the 'place' these ethnic malls 'make' for people that do not necessarily self-identify as part of the culture, and its 'place' as a part of the city.

The Toronto area generally prides itself in its multiculturalism, but it has not been without its detractors. Uzma Shakir, a Jane Jacob's Award winner and the director of the City of Toronto's Equity, Human Rights, and Diversity department, was quoted as saying "the multiculturalism discourse has suddenly shifted from struggling for inclusiveness...to having too much multiculturalism" (2011; as quoted in Galanaskis, 2013, p.70) in which the prevalence of cultural traditions and institutions from ethnic minorities is starting to make non-members feel uncomfortable. Though she may not agree with this sentiment, it recognizes the fact that people do have varying opinions on multiculturalism. Like the City of Toronto, the City of Markham is also known for its multiculturalism and is home not only to Chinese residents but people of many different backgrounds. That said Markham has indeed seen its share of the 'too much multiculturalism' discourse, as highlighted by a controversial incident relating to a former 
deputy mayor ${ }^{4}$ (Leung \& Lau, 2008). However as Sandercock writes, "a truly multicultural society not only encourages and supports community organizations within immigrant groups, but also works to incorporate immigrants into wider, cross-cultural activities and organizations" (Sandercock, 2003, p.136). A focus group of youth living in the Jane and Finch area conducted by Galanaskis was asked what their ideal public space is, and "all spoke of places that would be inclusive and bring together different groups of people" (2013, p.70). Most certainly the social interactions mentioned by Oldenburg and Jacobs as being so vital to creating a good public space and the shift in focus to public life should be extended to intercultural interactions. Gonzalez writes, "interculturalism happens in a variety of spaces such as schools, shops, and markets" (2011, as quoted in Galanaskis, 2013, p.80); which makes studying the intercultural interactions within ethnic malls, a commercial hub of the ethnoburbs, appropriate. Most of all, it is important from a city building perspective that initiatives are taken so that everyone is comfortable and welcoming to the demographic changes cities in Canada are facing.

\subsubsection{Experiences of non-ethnic patrons within ethnic malls}

The following section discusses situations I observed where ethnic malls are able to provide opportunities for intercultural interactions, creating a unique sense of place not found in conventional shopping malls.

While First Markham Place's main demographic is people of Chinese descent,

\footnotetext{
4 In 1995, then Deputy Mayor Carole Bell said that the growth of ethnic malls was driving away the 'back-bone' of Markham (ie. other non-Chinese Markham residents). This created an outcry from the public as well as twelve mayors in the Greater Toronto Area disassociating themselves from these remarks (DeMara, 1995)
} 
there were certain times during my field visits in which non-Chinese patrons had a larger presence than normal. As I was told by the property manager,

"Aside from people from Hong Kong or Mandarin speaking patrons from mainland China and Taiwan, we also have Korean, Vietnamese, and other Southeast Asians that visit the mall as well. At lunch time you will see even more non-Chinese people including Caucasians and South Asians" (Property Manager, personal communication, December 17, 2015).

When I did my weekday field visits during the lunch hour, it was instantly obvious what she meant as the number of non-Asians was noticeably greater, especially as I entered the food court. I observed many tables with varying mixes of ethnicities and age groups. Some of them were wearing business attire while others had identity cards, making it apparent that these were office and other workers that came to the mall for lunch. One group I interviewed consisted of one Chinese and two Caucasian males, and they told me "We come here at least once a week because we like the variety. Also the food here is relatively inexpensive" (Respondent AW, personal communication, January $29,2015)$. When I asked the non-Chinese patrons in the group if they would come here with their Chinese coworker accompanying them, they said they would. Indeed, another respondent of Iranian ethnicity said that he would come once a month to eat lunch, and normally ate alone (Respondent AX, personal communication, January 2015). Similarly, another group that I interviewed consisting of three Caucasians said that they also came here once a week because they only worked a two minute drive away and that they liked that the food was quick and inexpensive "(Respondent AY, personal communication, January 29, 2015). In fact, one Caucasian respondent that I interviewed 
on a Saturday afternoon was eating with his Caucasian girlfriend saying

"I was first introduced to First Markham Place's food court by my Asian coworker and now I come here to eat all the time, on top of our weekly visits during the weekdays for lunch. I especially like how unlike other food courts we don't have to wait in line and we can just sit down to wait for our food" (Respondent Al, personal communication, January 24, 2015).

The same respondent also said that he enjoyed walking around and looking at the stores even though he normally does not buy anything. He said that he finds the stores interesting because they are not the regular chain stores one sees in major conventional malls.

Aside from during lunch times, I did observe two non-Asian males in their middle age doing work and reading the newspaper in the food court on two separate occasions during weekday evenings. In addition there was one pair of mall visitors that I interviewed during Chinese New Years eve, one of which is a Chinese male while the other a Hispanic female. When asked if they had come to watch the countdown show, the male told me

"No I didn't know about the show beforehand. However I did know that there normally is something that goes on during Chinese New Year eve so I thought it would be a cool experience for my friend visiting from Peru. [When I asked how the female respondent was enjoying her time there, she replied] I find this very interesting. It feels like I am in China or something" (Respondent BN, personal communication, February 18, 2015).

In attendance that night was also Mayor Frank Scarpitti of the City of Markham. Known for singing Chinese songs during Chinese cultural events, he addressed the 
crowd saying, "First Markham Place is not only a place to shop, but really a place that brings the community together" (Scarpitti, 2015). His address not only acknowledges the role of First Markham Place as a hub for Markham's Chinese residents but its role as a significant place and symbol of multiculturalism within the city.

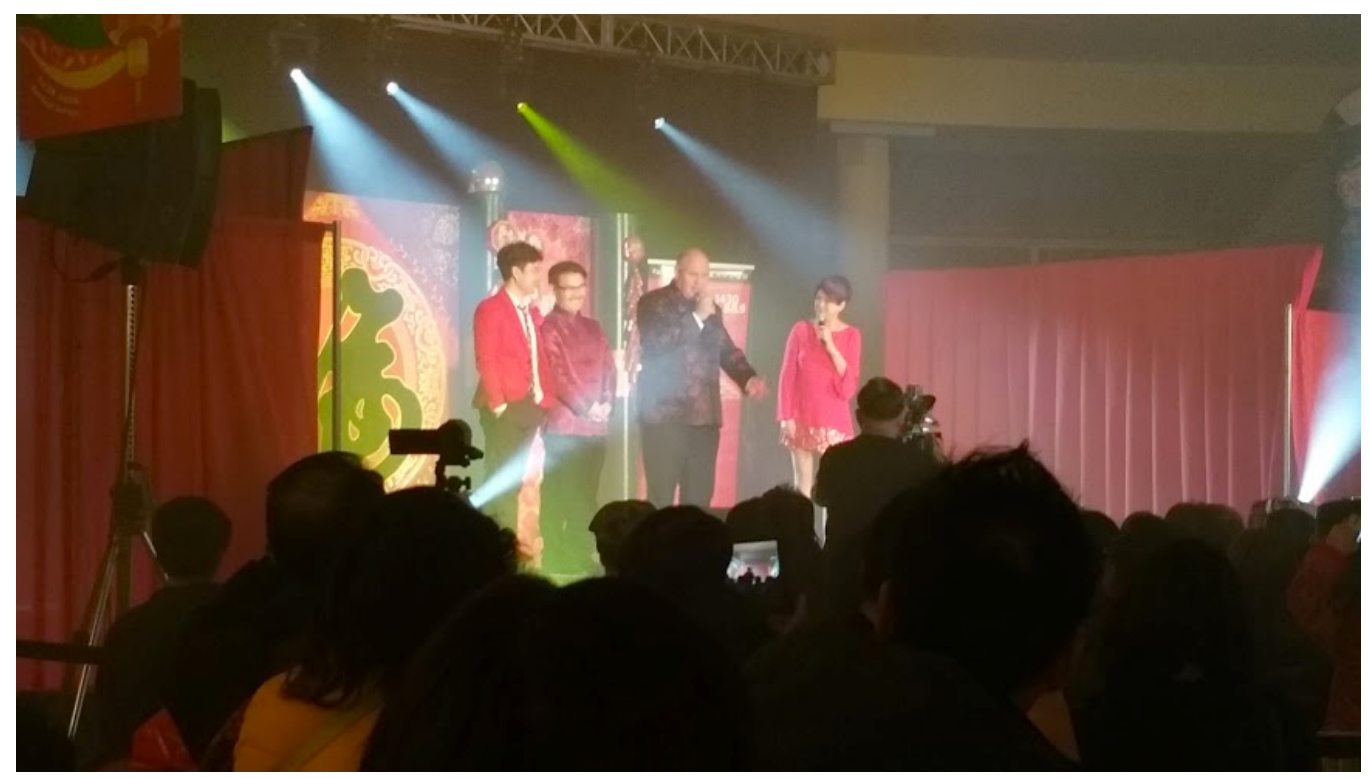

Figure 16 Mayor Frank Scarpitti of the City of Markham addressing the audience during the Chinese New Years Eve show

All these are examples of how ethnic malls are able to expose non-minorities the culture of the minorities living in their community, and also give them a venue to interact with each other in a unique cultural setting. Like what Lo wrote about ethnic enclaves being a "gateway for venturing into another culture" (Lo, 2009, p.393), the same can be said about ethnic malls. It provides the opportunity for them to not only accept all the different cultural groups in the community but also embrace it. Further it provides them a sense of place and belonging that, though different from the feelings of nostalgia and connection to ones ethnic background, is unique and apparent. 


\subsubsection{Physical manifestations of intercultural exchange}

Not everyone that is of an ethnicity outside of an ethnic mall's key demographic are comfortable with or feel the need to embrace other cultures, even if provided the venues to do so. One factor that appears to play a part in this has to do with the physical space. The following section discusses ways in which suburban ethnic shopping malls can provide a sense of familiarity or comfort to people not of the target ethnic demographic. One Caucasian woman interviewed stated that

"I prefer First Markham Place over Pacific Mall because the stores feel more similar to the ones that I am used to. The stores in Pacific Mall are too small and it becomes very overwhelming. It also helps that there are other non-Asian stores in the plaza like the Home Outiftters" (Respondent BQ, personal communication, February 27, 2015). (See Figure 16)

Likewise another Caucasian respondent stated that Pacific Mall was "too much" stating the same reasons, despite attending a Chinese church because her husband pastors at the church's English congregation and being "very comfortable around Chinese people" (Respondent BR, personal communication, February 27, 2015). Thus, it appears that the physical combination of conventional and ethnic mall attributes can encourage one to engage with and expose themselves to other cultures.

On the flip side, it appears many mainstream businesses see the use of embracing minority cultures through their products and marketing. Perhaps in the same way signage is an important part of placemaking for immigrants and ethnic minorities

(Pascoe, 1992; as quoted in Sandercock, 2003, p.136), visual cues by mainstream businesses can be an important intercultural placemaking mechanism reflecting the 
distinctiveness of ethnic malls.

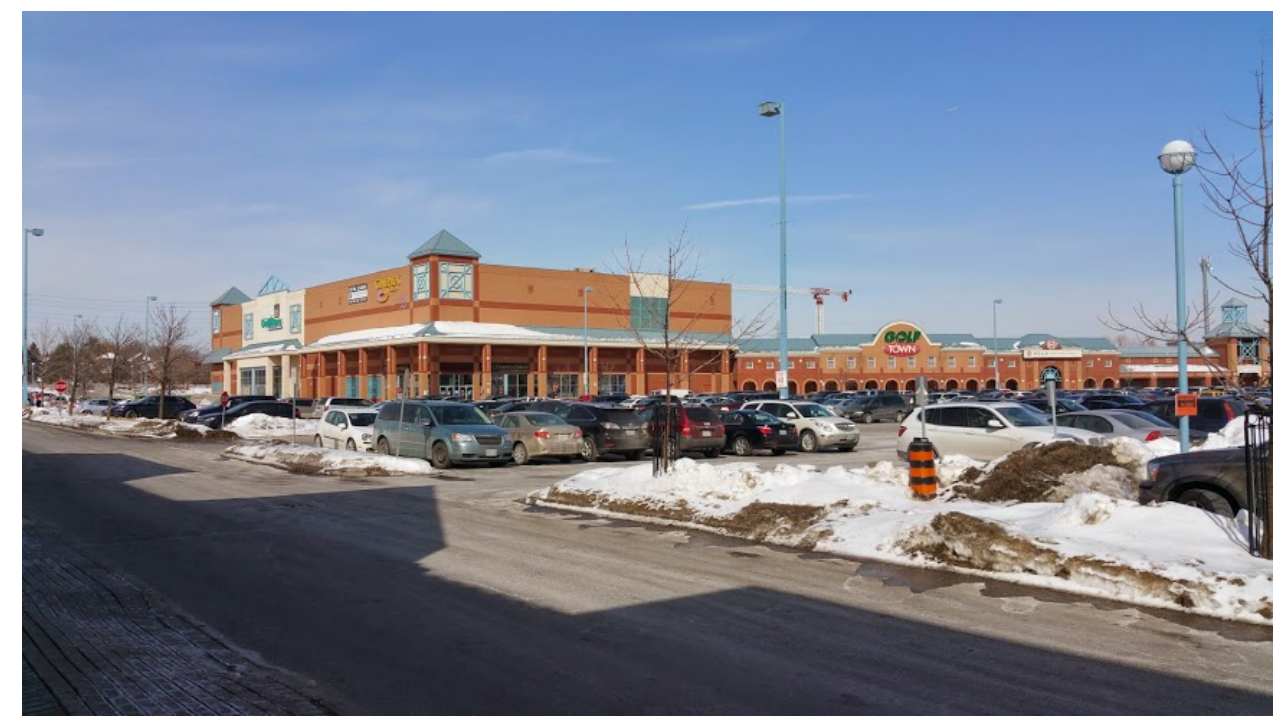

Figure 17. A view of Home Outfitters, Cineplex Odeon, and Golf Town at First Markham Place

Examples of this include Chinese advertisements for mainstream businesses such as Bell Canada, as well as Canada Dry branded Chinese New Year decorations (See Figure 18). These visual forms of interculturalism connecting mainstream businesses to certain cultural features not only create a unique environment, but it may also help immigrant mall patrons feel a sense of belonging within Canadian society.

Thus while ethnic malls do not necessarily provide a sense of place to patrons not part of the target ethnicity through nostalgia or familiarity, it does provide a unique sense of place facilitated by the intercultural interactions that is fostered by the shopping centre. It provides a special sense of belonging to both non-members of the ethnicity exploring new cultures in a mostly comfortable environment, while also acting as a bridge for ethnic minorities between their own culture and the current society they are now part of. 

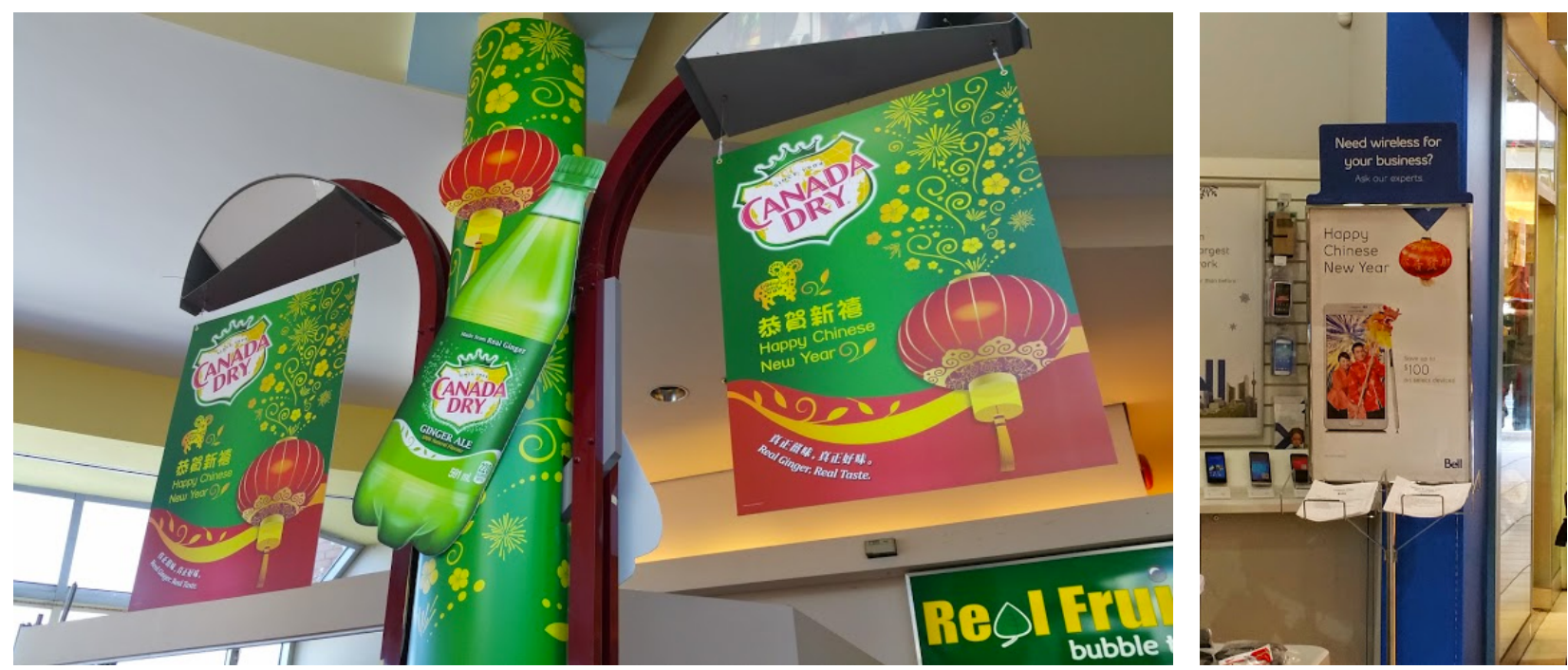

Figure 18. Chinese New Year decorations sponsored by Canada Dry, and a Bell Canada advertisement for Chinese New Year 


\subsection{CHAPTER V: Conclusions \& Next Steps}

\subsection{OVERALL INSIGHTS AND ADDITIONAL ANALYSIS}

The analysis I conducted from my field observations and interview responses as informed by the literature written on placemaking within ethnoburbs and suburban shopping centres has provided me some insights on my initial research questions.

First, it appears that shopping centres can and often do provide physical environments for the public to use aside from just being a place for people to purchase products and services. The closer-knit nature of ethnic communities within ethnoburbs and the lack of chain stores for independently-owned stores means that these retail environments are relatively more able to encourage social interactions and relationships, whether between mall patrons or between shopkeepers and customers, than in today's conventional suburban malls. However for the most part, the independent, 'suburban mindset' still apparently exists as people generally keep to themselves or the groups they are already in.

Next, ethnic malls are able to provide products and services that cater to the preferences of the ethnic minorities they cater to. Not only does this satisfy certain personal preferences, but also it is able to connect first or later-generation immigrants back to their cultural heritage, in turn giving ethnic malls a unique sense of place. This is further facilitated through cultural events hosted by ethnic malls in which they become a natural venue. However it seems that the variety and quantity of goods, particularly nonfood products, available at conventional malls outweighs innate desires for the 'sense of place' provided by ethnic malls. Furthermore as future generations start to lose touch 
from their cultural heritage, the strength of this sense of place may diminish.

Finally, ethnic malls create venues in which intercultural interactions can occur. However not everyone outside the target ethnic community have the will to embrace the foreign culture. This may be due to the internal strength of the ethnic community but also the way physical spaces are designed as well as degree of homogeneity within these spaces.

\subsection{IMPLICATIONS FOR PLANNING}

While the quality of suburban ethnic malls as public spaces and the extent to which they provide a sense of place can benefit from further research, this study has proven that their potential is apparent and worth enhancing. This section will provide some planning implications that should be noted in protecting and strengthening the placemaking qualities of ethnic malls.

As mentioned in section 2.1.2 Land Use Planning for Multicultural

Communities of the literature review, there is an apparent need to enhance multicultural policies and recognize the way in which they influence land use planning.

As an example, a quick look at local policies in Markham shows that there is room for improvement in multicultural policies in relation to land use planning. Though the City established a Diversity Action Plan in 2010, the only recommended action for the development services commission, of which planning and urban design falls under at the City, is to diversify types of housing and for general intensification. No reference to ethnic retailing was made. Likewise, while there is mention of Pacific Mall being a place in which "it's not just the shopping that attracts the crowds, but the community events" 
(City of Markham, 2010, p.21), it does not provide any action plans regarding how to leverage these retail spaces as community spaces through partnerships or any other initiatives. Similarly, with the exception of s. 2.2.2.7 which states the need to "celebrate cultural diversity and uniqueness through planning for the needs of all members of the community" (City of Markham, 2014), no specific policy provides further guidance on how this can be done in the Official Plan.

References to the unique needs of ethnic minorities is also lacking in higher levels of policies. At the regional level, York Region's Official Plan only mentions the cultural diversity of its residents and the need to respect and 'celebrate' it. The only more practical policy is section 3.3.4, which mentions the need to "encourage the co-location or campusing of human services with other uses such as recreational, public buildings and arts and cultural facilities" (York Region, 2010). Taking into consideration existing academic literature and my own research, there is clearly a lot more potential for this policy to be expanded. The policy fails to recognize the unique needs of various cultures. As made apparent in my research, space is experienced and utilized differently by different cultures. Whether it be seniors using mall space for tai chi or the mall being the best venue for connecting second generation ethnic minorities back to their cultural roots, cultural diversity creates unique land use implications that is not seen in less culturally diverse communities. Therefore it is worth expanding the policy so that these unique needs are at least recognized and institutionalized, and that at least a framework is provided from a land use perspective when planning for multicultural communities. Likewise, cultural diversity is only briefly mentioned in the Provincial Policy Statement 
(2014), again without expanding on what implications cultural diversity actually has. While there is much focus on the cultural heritage of Ontario, which most definitely is important, the new culture heritage being created in the present is mostly ignored. Again there is room for improvement in land use planning policies relating to the planning for a multicultural society.

While this paper does not necessarily recommend encouraging more ethnic retail spaces as the market may not always allow for it nor will more necessarily mean better ethnic retail spaces, this paper does imply that the significance of multicultural planning within land use planning should be further recognized. Only by institutionalizing land use planning to account for cultural considerations can proper steps be taken in multicultural planning.

Finally, looking back at the mention of co-locating land uses in section 3.3.4 of York Region's Official Plan, it appears that this is another area of policy that has room for expansion. As my research has made apparent, the potential of co-location is very significant. Whether it is the ethnic mall being a venue for social interactions or informal gatherings, as a place for community events, or as a place for residents to relax, private retail landscapes are an excellent example of the vast potential of co-locating various land uses. Therefore policies should further recognize the existence and perhaps potential for various land uses beyond existing confines of land use designations.

\subsection{NEXT STEPS FOR FUTURE RESEARCH}

Due to the limitations outlined in section 3.1.4 and observations made in my findings, the following are some next steps for future research that will advance some of 
the research topics covered in this paper:

- This paper looks only at one shopping centre, First Markham Place, as a case study. Thus, the extent to which the analyses and implications made in this paper can be extended to other Chinese ethnic retail landscapes may be limited. Therefore, research can be conducted on other Chinese and/or East Asian ethnic retail centres that vary in size and location. Further research within First Markham Place can also be conducted but with a larger, more controlled sample and/or during a different time of the year.

- The findings in this paper can also benefit from further research in ethnic shopping centres not targeted primarily to people of Chinese ethnicity. By expanding the research to non-Chinese ethnic retail landscapes, one will be able to determine to what extent the findings made in this paper can be fully extended to other ethnocultural groups as well.

- Some findings in this paper are made relative to conventional, suburban shopping centres. Therefore the research conducted in this paper would benefit from further research on the placemaking qualities of conventional shopping centres and how mall patrons use those spaces as alternatives to public space.

\subsection{FINAL THOUGHTS}

After conducting a series of field visits speaking to mall patrons and observing how they use suburban ethnic retail spaces, it is clear that these spaces can provide quality alternatives to public spaces in a way conventional shopping malls are relatively less able to do. Further, they are able to provide a unique sense of place as both venues in 
which one can connect to their own cultural identity, or as important venues for intercultural exchange vital to communities that identity themselves as multicultural. However, the extent to which different placemaking characteristics are effective depends both on the individual's own characteristics and also the space. The exact formula required to maximize such placemaking characteristics, if such formula exists, is complex and calls for further research. Still, the fact that the unique cultural component of these malls plays a role in placemaking is apparent. 


\section{APPENDICES}

\section{Appendix 1: Respondents List}

\begin{tabular}{|c|c|c|c|c|c|c|c|}
\hline ID & DATE & TIME & AGE & GENDER & ETHNICITY & $\begin{array}{r}\text { YEARS } \\
\text { IN CANADA }\end{array}$ & $\begin{array}{r}\text { TRAVEL TIME } \\
\text { TO FMP }\end{array}$ \\
\hline AA & 12-Jan & 7:03 & $25-34$ & Male & Chinese (HK) & 17 & 15 \\
\hline$A B$ & 12-Jan & $7: 10$ & $35-44$ & Male & Chinese (HK) & 20 & 10 \\
\hline$A C$ & 21-Jan & $6: 20$ & $25-34$ & Female & Chinese (HK) & 23 & 25 \\
\hline$A D$ & 21-Jan & $6: 15$ & $35-44$ & Male & Indonesian & 35 & 15 \\
\hline $\mathrm{AE}$ & 21-Jan & $6: 40$ & $25-34$ & Male & Chinese & Born & 10 \\
\hline$A F$ & 24-Jan & $3: 00$ & $18-24$ & Male & Chinese & Born & 12 \\
\hline$A G$ & 24-Jan & $3: 15$ & $35-44$ & Female & Chinese & 8 & 20 \\
\hline $\mathrm{AH}$ & 24-Jan & $3: 20$ & $45-54$ & Female & Chinese (HK) & 30 & 20 \\
\hline $\mathrm{Al}$ & 24-Jan & $3: 40$ & $18-24$ & Male & Canadian & Born & 10 \\
\hline AJ & 24-Jan & $3: 45$ & $18-24$ & Male & Chinese & 12 & 15 \\
\hline AK & 24-Jan & 4:00 & $18-24$ & Female & Chinese & 12 & 20 \\
\hline$A L$ & 24-Jan & $4: 12$ & $55-64$ & Female & Chinese (HK) & 40 & 5 \\
\hline AM & 24-Jan & $4: 15$ & $18-24$ & Female & Chinese-Viet & Born & 8 \\
\hline AN & 24-Jan & $4: 25$ & $25-34$ & Male & Chinese (HK) & 19 & 10 \\
\hline $\mathrm{AO}$ & 25-Jan & 4:00 & $55-64$ & Male & Chinese (HK) & 41 & 15 \\
\hline AP & 25-Jan & $4: 10$ & $25-34$ & Male & Chinese & 7 & 10 \\
\hline$A Q$ & 25-Jan & $4: 30$ & $18-24$ & Female & Chinese & Born & 15 \\
\hline AR & 25-Jan & $4: 45$ & $25-34$ & Female & Chinese & 15 & 20 \\
\hline AS & 27-Jan & $6: 00$ & $35-44$ & Female & Chinese & 13 & 15 \\
\hline AT & 27-Jan & $6: 30$ & $35-44$ & Female & Chinese & 20 & 20 \\
\hline $\mathrm{AU}$ & 27-Jan & $6: 45$ & 65 or over & Male & Chinese (HK) & 20 & 15 \\
\hline AV & 27-Jan & $6: 50$ & $35-44$ & Male & Chinese (HK) & 20 & 5 \\
\hline AW & 29-Jan & $12: 00$ & $25-34$ & Male $x 3$ & Multicultural & Multiple & 5 \\
\hline$A X$ & 29-Jan & $12: 15$ & $45-54$ & Male & Iran & 25 & 20 \\
\hline AY & 29-Jan & $12: 20$ & Multiple & Male x3 & Multicultural & Multiple & 5 \\
\hline$A Z$ & 16-Feb & $5: 05$ & Multiple & Multiple & Filipino & Multiple & Multiple \\
\hline BA & 16-Feb & $5: 10$ & $18,45,55$ & Multiple & Chinese & Multiple & Multiple \\
\hline BB & 16-Feb & $4: 46$ & $18-24$ & Male & Filipino & 10 & 50 \\
\hline $\mathrm{BC}$ & 16-Feb & $4: 55$ & $18-24$ & Male $\times 2$ & Chinese & Born & 8 \\
\hline $\mathrm{BD}$ & 16-Feb & $5: 00$ & $25-34$ & Male & Chinese & 5 & 10 \\
\hline$B E$ & 16-Feb & $5: 10$ & $25-34$ & Female $\times 2$ & Chinese & Born & 8 \\
\hline $\mathrm{BF}$ & 18-Feb & $10: 30$ & 65 or over & Male & Chinese (HK) & 43 & 10 \\
\hline BG & 18-Feb & $10: 35$ & $55-64$ & Male \& Female & Chinese & 15 & 7 \\
\hline $\mathrm{BH}$ & 18-Feb & $10: 40$ & $45-54$ & Male & Chinese & 20 & 10 \\
\hline $\mathrm{BI}$ & 18-Feb & $10: 48$ & $35-44$ & Male \& Female & Chinese & 8 & 10 \\
\hline BJ & 18-Feb & $10: 53$ & $18,18,45$ & $F, F, M$ & Chinese & Multiple & 15 \\
\hline $\mathrm{BK}$ & 18-Feb & $10: 59$ & $18,45,45$ & $\mathrm{M}, \mathrm{M}, \mathrm{F}$ & Chinese & Born & 10 \\
\hline$B L$ & 19-Feb & $4: 45$ & $18,45,45$ & $M F F$ & Chinese & Multiple & 8 \\
\hline BM & 19-Feb & $4: 50$ & $<18,65$ & Female $\times 2$ & Chinese & 23 & 10 \\
\hline $\mathrm{BN}$ & 19-Feb & $5: 30$ & $55-64$ & Female & Chinese & 20 & 10 \\
\hline BO & 27-Feb & $8: 45$ & 65 or over & Female & Chinese & 25 & 8 \\
\hline $\mathrm{BP}$ & 27-Feb & 9:00 & $45-54$ & Male & Chinese & 25 & 10 \\
\hline$B Q$ & 27-Feb & $9: 15$ & $45-54$ & Female & Canadian & Born & 10 \\
\hline $\mathrm{BR}$ & 27-Feb & $9: 20$ & $55-64$ & Female & Canadian & Born & 15 \\
\hline
\end{tabular}

* Multiple means more than one person was interviewed and there were no opportunity to note individual attributes.

** For age groups when looking at group interviews, 18 is the short form for $18-24,45$ for $45-54$, and $\mathbf{5 5}$ for $55-64$ 
Appendix 2: Optional Activities \& Necessary Activities (Gehl, et al., 2006, as quoted in Gehl \& Svarre, 2013, p.26)

Optional activities

(Take place under good external conditions)
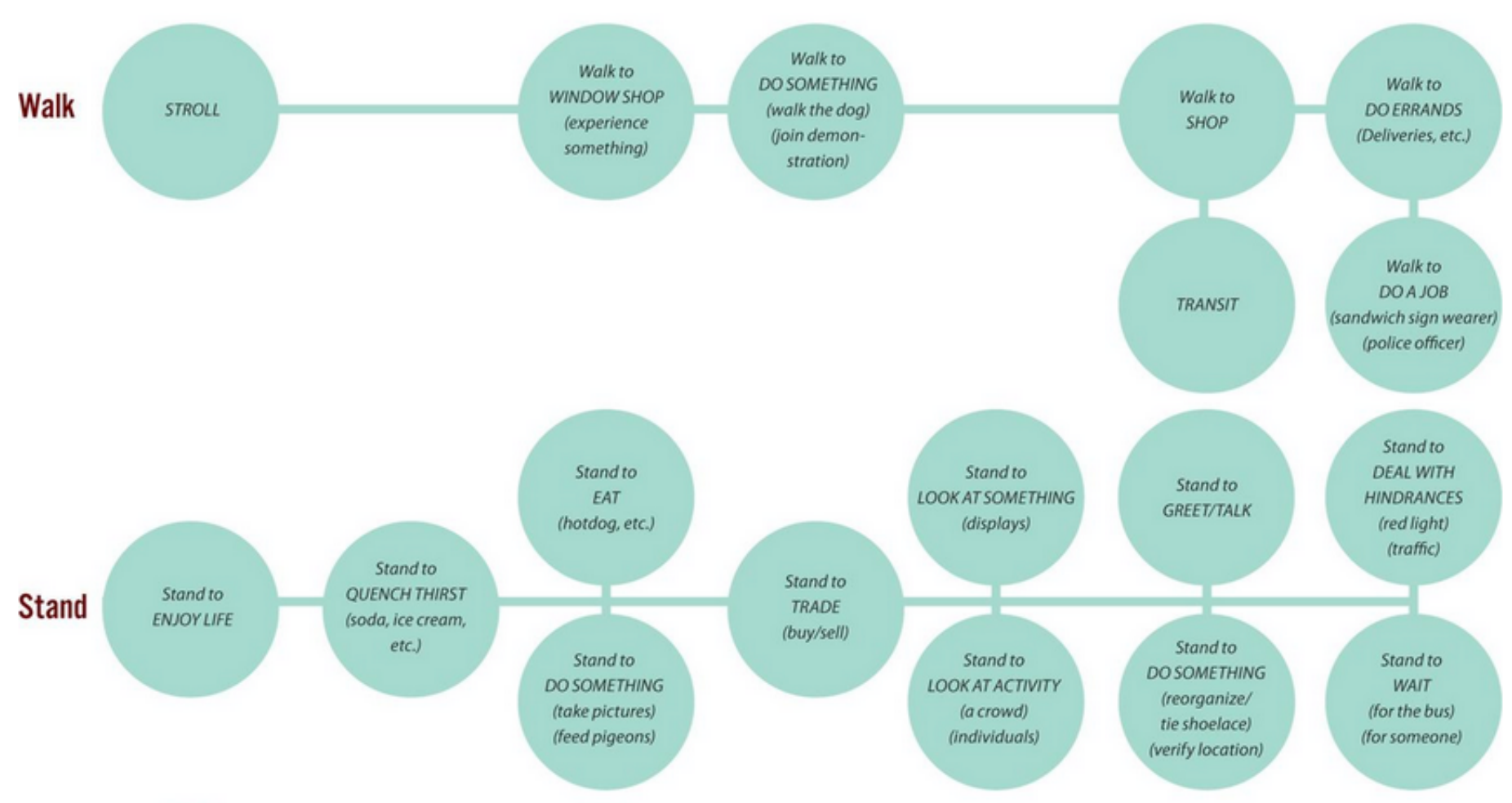

Sit
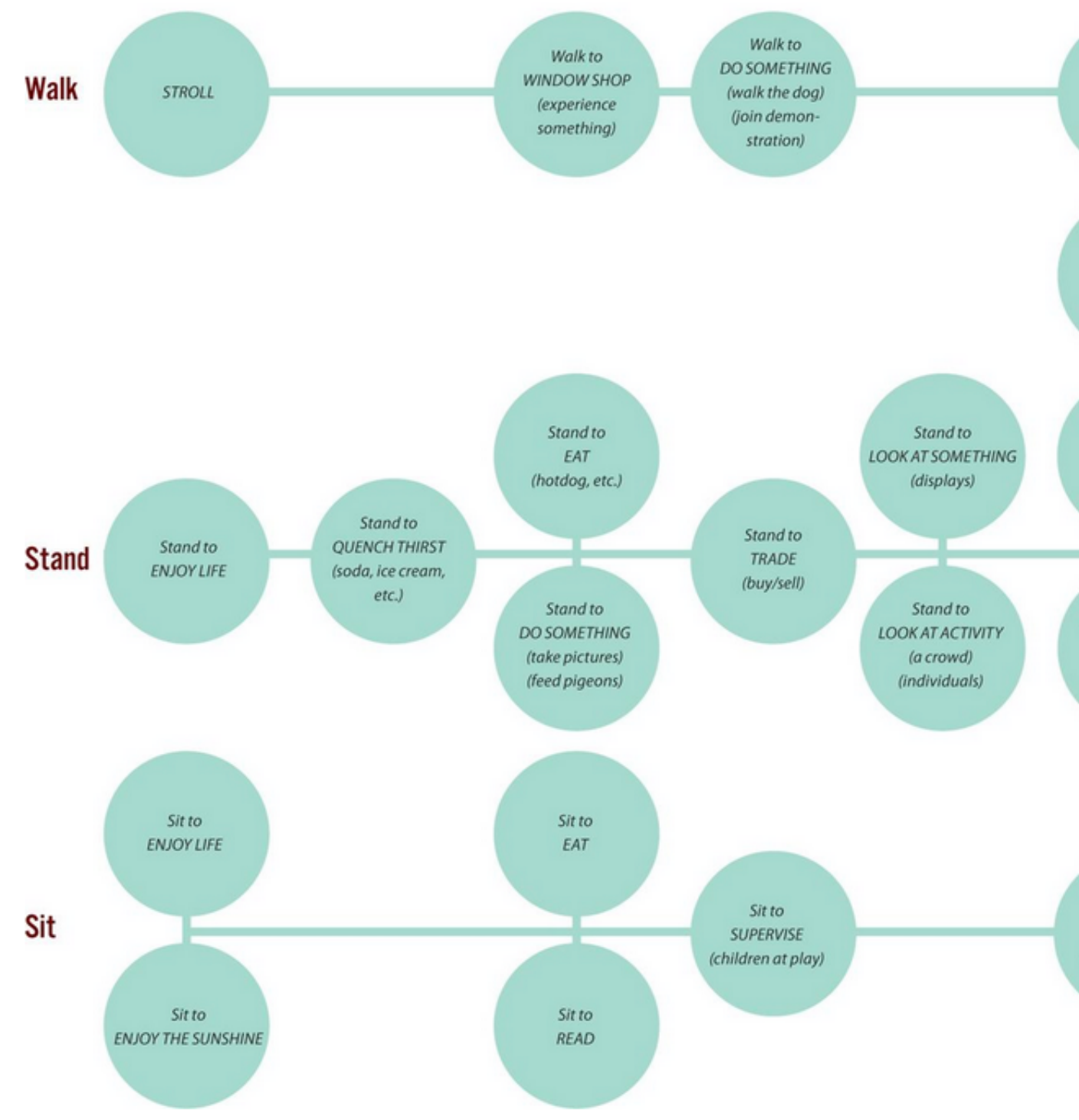

TRANSIT

Necessary activities

(Take place under all conditions)

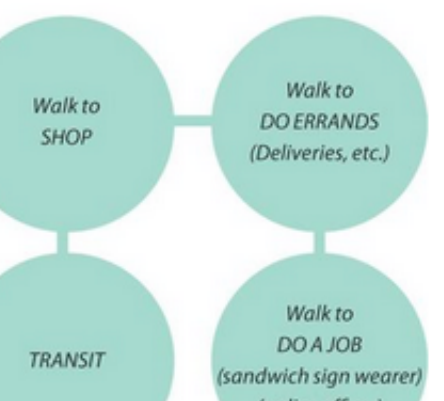

(police officer) 


\section{REFERENCES}

An Urbanist Says a Sense of Place is More Important than the Design Itself. (2000, April 1). Architectural Record.

Andranovich, G., \& Riposa, G. (1993). Data Collection in the Urban Setting. In Doing Urban Research (pp. 62-86). Thousand Oaks, California: SAGE Publications.

Banerjee, T. (2001). The future of public space: Beyond invented streets and reinvented places. Journal of the American Planning Association, 67(1), 9-24.

Brill, M. (2001). Mistaking Community Life for Public Life. E: Places, 14(2), 48-55.

Cohen, L. (2008). A Consumers' Republic: The Politics of Mass Consumption in Postwar America. Knopf Doubleday Publishing Group.

DeMara, B (1995). Mayors condemn comments on Chinese," Toronto Star. September 16, 1995, A4.

DiscoverOntario. (n.d.). Retrieved April 11, 2015, from

http://www.vaughanmills.com/About/Discover-Ontario-at-Vaughan-Mills.aspx

Galanakis, M. (2013). Intercultural public spaces in multicultural toronto. Canadian Journal of Urban Research, 22(1), 67-89.

Gillem, M. (2009). Make-believe main streets: Hyperreality and the lifestyle center. TDSR,2009(11), 13-26.

Gehl, J., \& Svarre, B. (2013). How to study public life. Washington DC: Island Press.

Glazer, N., \& Moynihan, D. P. (1963). beyond the melting pot: the negroes, Puerto ricans, jews, italians, and irish of new york city. Cambridge, MA: MIT Press.

Good, Kristin. (2005). Patterns of politics in Canada's immigrant-receiving cities and suburbs: How settlement patterns shape the municipal role in multiculturalism policy. Policy Studies. 26, 3 and 4: 261-289.

Huang, Y., Oppewal, H., \& Mavondo, F. (2011). The influence of ethnic attributes on ethnic consumer choice of service outlet. European Journal of Marketing, 47(5), 877-898.

Jacobs, J. (1961). The death and life of great american cities. (p. 3-30). New York, NY. 
Kowinski, W. (1985). The Malling of america: an inside look at the greater consumer paradise. New York: William Morrrow and Company.

Laniado, L. (2002). Place making in new retail developments: The role of local, independently owned businesses. Cambridge, MA: Massachusetts Institute of Technology.

Leung, H., \& Lau, R. (2008). Multiculturalism at Work: Pacific Mall in Toronto as a Case Study.Investigating Diversity: Race, Ethnicity, and Beyond, 111-120.

Li, W. (1997). Anatomy of a new ethnic settlement: The chinese ethnoburb in los angeles. Urban Studies,35(3), 479-501.

Liu, et al (2014). Ethnic enterprises and community development. GeoJournal , 79, 565576.

Lo, L., \& Preston, V. (2000). Asian theme malls in suburban toronto: land use conflict in richmond hill. Canadian Geographer, 44(2), 182-190.

Lo, L. (2009). The role of ethnicity in the geography of consumption. Urban Geography, 2009(30), 391-415.

Lowes, M. (2002). Indy dreams and urban nightmares: Speed merchants, spectacle, and the struggle over public space in the world-class city. Toronto, Ontario: University of Toronto Press.

Malenfant et al. (2009). Projections of the diversity of the Canadian population, 2006 to 2031. Retrieved from website: http://www.statcan.gc.ca/pub/91-551-x/91-551x2010001-eng.htm

Manzo, L. (2003). Beyond house and haven: Toward a revisioning of emotional relationships with places. Journal of Environment Psychology,23, 47-61.

Markham Diversity Action Plan. (2010). Retrieved March 3, 2015, from http://www.markham.ca/wps/portal/Markham/AboutMarkham/Diversity/

Markham Official Plan. (2014). Retrieved March 3, 2015, from https://www.markham.ca/wps/portal/Markham/BusinessDevelopment/PlanningAnd DevelopmentServices/OPZoning

Meyer, W. (2013, April 13). The End of full-time work in the american retail service Sector. Forbes. 
Myles, J., \& Hou, F. (2004). Changing colours: Spatial assimilation and new racial minority immigrants. The Canadian Journal of Sociology, 29(1), 29-58.

Neuman, W. L. (2010). Social research methods: Qualitative and quantitative approaches. (7th ed.). Boston: Pearson Education Inc.

Oldenburg, R. (1989). The great good place. Da Capo Press.

Parlette, V., \& Cowen, D. (2010). Dead malls: Suburban activism, local spaces, global logistics. International Journal of Urban and Regional Research.

Planning Act. (1990). Retrieved from http://www.elaws.gov.on.ca/html/statutes/english/elaws_statutes_90p13_e.htm

Pride, W., \& Ferrell, O. (2010). Marketing. Cengage Learning.

Provincial policy statement. (2014). Retrieved from http://www.mah.gov.on.ca/AssetFactory.aspx?did=10463

Qadeer, M. et al. (2010). Evolution of ethnic enclaves in the toronto metropolitan area, 2001-2006. Int. Migration \& Integration, 11, 315-339.

Qadeer, M., \& Kumar, S. (2006). Ethnic enclaves and social cohesion. Canadian Journal of Urban Research, 15(2), 1-17.

Ross, L. (2007, March 15). Applying the principles of placemaking to effect a more dynamic downtown. Downtown Idea Exchange.

Rybcyznski, W. (1993). The New Downtowns. Atlantic Monthly. 271: 98 -106.

Rybczynski, W. (1999). Why we need Olmsted again. Wilson Quarterly. 15.

Sandercock, L. (2003). Mongrel cities in the 21st century. London, England: Continuum International Publishing Group.

Scharoun, L. (1979). America at the mall: the cultural role of a retail utopia. Jefferson, North Carolina: McFarland \& Company Inc. Publishers.

Social Responsibility. (2014, January 1). Retrieved April 11, 2015, from http://www.cadillacfairview.com/social-responsibility/

Sorensen, C. (2015). Mapped: 10 years of unprecedented change in Canada's cities. Maclean's. 
Statistics Canada, (2011). Immigration and ethnocultural diversity in canada. Retrieved from website: http://www12.statcan.gc.ca/nhs-enm/2011/as-sa/99-010-x/99-010x2011001-eng.cfm

Statistics Canada, (2011). The Canadian population in 2011: Population counts and growth. Retrieved from website: http://www12.statcan.ca/censusrecensement/2011/as-sa/98-310-x/98-310-x2011001-eng.cfm

Stimson, J. (n.d.). The Disadvantages of 12-hour work shifts. Houston Chronicle.

Twigger-Ross, C. L., \& Uzzell, D. K. (1996). Place and identity processes. Journal of Environment Psychology, 16, 205-220.

Wang, S., Hii, R., Zhong, J., \& Du, P. (2013). Recent trends of ethnic chinese retailing in metropolitan toronto. International Journal of Applied Geospatial Research, 4(1), 49-66.

Wen, M. (2009). Ethnic neighborhoods in multi-ethnic america, 1990-2000: Resurgent ethnicity in the ethnoburbs?. Social Forces, 88(1), 425-460.

Wen, Y. (2015). Combined Material Recycling Study with Aesthetic of Entropy and Place Making. The Scientific World Journal, 2015. Retrieved from http://www.hindawi.com/journals/tswj/2015/208342/

Whyte, W. H. (1980). The Social Life of Small Urban Spaces. Washington, D.C.

York Region Official Plan 2010 (consolidated 2013), Office of the Chief Administrative Officers 